University of Wollongong

Research Online

Faculty of Business - Papers (Archive)

Faculty of Business and Law

2017

\title{
An empirical analysis of algorithmic trading around earnings announcements
}

\author{
Alex Frino \\ University of Wollongong, afrino@uow.edu.au \\ Tina Prodromou \\ University of Sydney \\ George Wang \\ George Mason University \\ P Westerholm \\ University of Sydney
}

Hui Zheng

University of Sydney

Follow this and additional works at: https://ro.uow.edu.au/buspapers

Part of the Business Commons

Research Online is the open access institutional repository for the University of Wollongong. For further information contact the UOW Library: research-pubs@uow.edu.au 


\title{
An empirical analysis of algorithmic trading around earnings announcements
}

\author{
Abstract \\ This study examines the impact of corporate earnings announcements on trading activity and speed of \\ price adjustment, analyzing algorithmic and non-algorithmic trades during the immediate period pre- and \\ post-corporate earnings announcements. We confirm that algorithms react faster and more correctly to \\ announcements than non-algorithmic traders. During the initial surge in trading activity in the first 90 . $s$ \\ after the announcement, algorithms time their trades better than non-algorithmic traders, hence \\ algorithms tend to be profitable, while non-algorithmic traders make losing trades over the same time \\ period. During the pre-announcement period, non-algorithmic volume imbalance leads algorithmic volume \\ imbalance, however, in the post announcement period, the direction of the lead-lag association is exactly \\ reversed. Our results suggest that as algorithms are the fastest traders, their trading accelerates the \\ information incorporation process. \\ Disciplines \\ Business \\ Publication Details \\ Frino, A., Prodromou, T., Wang, G. H. K., Westerholm, P. \& Zheng, H. (2017). An empirical analysis of \\ algorithmic trading around earnings announcements. Pacific-Basin Finance Journal, 45 34-51.
}




\title{
An Empirical Analysis of Algorithmic Trading around Earnings Announcements
}

\author{
Alex Frino $^{\mathrm{a}}$, Tina Prodromou ${ }^{\mathrm{b}}$, George H. K. Wang ${ }^{\mathrm{c}}$ *, P. Joakim \\ Westerholm ${ }^{\mathrm{d}}$, Hui Zheng ${ }^{\mathrm{e}}$
}

April 2016

JEL classification: G14; G12

Keywords: Algorithmic Trading, Earnings Announcements, Market Efficiency

\footnotetext{
aniversity of Wollongong, NSW, Australia. b, d, e, The University of Sydney Business School, Sydney, NSW,

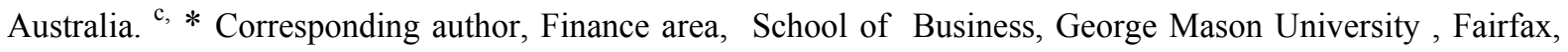
VA. USA 22030. Phone: 703-993-3415, E-mail address :gwang2@gmu.edu

We thank the Australian Securities Exchange for providing the data, and participants at the Financial Management Association Annual Meeting 2013, Financial Management Association Asia Annual Meeting 2013, 27 $7^{\text {th }}$ Australasian Finance and Banking Conference and Symposium on Financial Econometrics and Market Microstructure at Deakin University and seminars held at the Capital Market Cooperative Research Center, George Mason University and the University of Sydney for helpful comments. In particular, we thank Talis Putnins for sharing the computer code to calculate the information leadership shares, and an anonymous referee whose comments significantly improve our paper.
} 


\title{
An Empirical Analysis of Algorithmic Trading around Earnings Announcements
}

\begin{abstract}
This study examines the impact of corporate earnings announcements on trading activity and speed of price adjustment, analyzing algorithmic and non-algorithmic trades during the immediate period pre- and post- corporate earnings announcements. We confirm that algorithms react faster and more correctly to announcements than non-algorithmic traders. During the initial surge in trading activity in the first 90 seconds after the announcement, algorithms time their trades better than non-algorithmic traders, hence algorithms tend to be profitable, while non-algorithmic traders make losing trades over the same time period. During the pre-announcement period, non-algorithmic volume imbalance leads algorithmic volume imbalance, however, in the post announcement period, the direction of the lead-lag association is exactly reversed. Our results suggest that as algorithms are the fastest traders, their trading accelerates the information incorporation process.
\end{abstract}




\section{Introduction}

Hendershott, Jones and Menkveld (2011) show that algorithmic trades [AT] reduce private information and increase public information. In this paper we describe the actual process in which $\mathrm{AT}^{1}$ accelerate the incorporation of information. We use a unique dataset obtained from the Australian Securities Exchange [ASX], where price sensitive information is timely and exclusively released to the public during trading hours due to regulated continuous disclosure requirements. This study sets out to provide the first empirical evidence on whether AT react more rapidly to information, employ profitable trading strategies and lead or lag non-algorithmic traders [non-AT].

The traditional view in financial economics (e.g. French and Roll, 1986) is that public information is reflected in prices before anyone is able to trade on it. Theoretical studies by Grossman and Stiglitz (1980), Kyle (1985) and others on the other hand argue that private information is reflected in prices as a result of trading. The new algorithms active in the market today may potentially alter this clear distinction between public and private information, as fast decision making algorithms may trigger trades in the space between the moment when earnings are released and the moment when the information becomes public.

While some studies investigate the connection between informed trading and high frequency trading HFT (e.g., Hendershott and Riordan, 2011, Brogaard, 2010, and Brogaard, Hendershott and Riordan, 2014), no previous study has been able to determine why AT would be informed. ${ }^{2}$ Ederington and Lee (1993, 1995) and Fleming and Remolona (1999) show that a local equilibrium price level is established very rapidly, within minutes after

\footnotetext{
${ }^{1}$ In this paper we use the term AT for algorithmic trading rather than the popular term HFT for high frequency trading, to indicate that our data includes all trades submitted by a computer, slow and fast. ${ }^{2}$ Natural language processing that reads and interprets news text automatically may be one technique implemented making it possible for AT to respond to news arrivals quickly and in the correct direction with regards to the impact of the news on prices.
} 
macroeconomic announcements. Erenburg, Kurov and Lasser (2006) show that in this fast price discovery process, local futures traders are able to react more quickly to macroeconomic news announcements than off exchange traders. The information contained in corporate earnings announcements are also reflected rapidly in prices, but less so than macroeconomic announcements due to post-earnings announcement drift (see Bernard and Thomas, 1989, and later references to them). Campbell, Ramadorai, and Schwartz (2009) find that institutions anticipate both earnings surprises and post-earnings announcement drift, indicating that there indeed is a category of investors with access to superior or private information around earnings releases and also that this private information is not immediately reflected in securities prices.

Hence it appears that there is opportunity for algorithms to exploit mispricing and delayed reaction to new information within the first minutes after a public earnings release. One type of information-based trading that AT has the potential to do well is to detect informed trading. 'Information oriented technical traders' do not process private information, but aim to recognize price patterns caused by systematic mistakes by informed traders or predictable price impact from uninformed trades, p. 230, Harris (2003). Information oriented technical traders become informed when they trade based on actions by informed traders and such activity may become more effective with the help of fast automated trading technology. AT strategies are more likely to be used by traders that aim to be the first to react correctly to new information. It has been established that algorithms process information faster, see e.g. episodes when algorithms react to incorrectly published news. ${ }^{3}$ Kirilenko, Kyle, Samadi and

\footnotetext{
${ }^{3}$ http://libertystreeteconomics.newyorkfed.org/2011/10/how-well-do-financial-markets-separate-newsfrom-noise-evidence-from-an-internet-blooper.html provides an example of these rare events:

"News moves at high speed in the digital world and high-frequency-trading robots can trade faster than you can blink. In combination, these two powers can move markets up or down instantaneously. High frequency trading robots that are used to search for news events can exacerbate the speed and severity of crashes if the information is false. A particular case occurred on September 8, 2008, when a 2002 article about the bankruptcy of United Airlines's parent company resurfaced on the Internet
} 
Tuzun (2011) also confirm that high frequency traders aggressively trade in the direction of price changes. Brogaard, Hagstromer, Norden and Riordan (2015) show that those HFT practicing exchange members who invest in the fastest available connections reduce their adverse selection costs and gain market share. Biais, Foucault, and Moinas (2015) analyze the conditions under which the utilitarian welfare is maximized in a market where fast and slow traders coexist, and Brogaard, Hendershott and Riordan (2014, p. 2267) conclude that "HFTs facilitate price efficiency by trading in the direction of permanent price changes and in the opposite direction of transitory pricing errors". The question remains, do algorithms normally react not only fastest but also in the correct direction when news is released?

In this paper the information content of AT is investigated using a unique dataset where trades that are generated by an algorithm can be distinguished from manual and computerized manual order flow. The advantage of this dataset is that it enables us to differentiate the identity and exact originating trading terminal of each order submitted through an electronic order submission system, rather than having to rely on proxies like high frequency trades and fleeting orders (e.g., Hasbrouck and Saar (2009) and Hendershott, Jones, and Menkveld (2011)). Hence, the trading behavior we study is closer to the true behavior of AT than what has been possible in most previous studies.

Since no previous study has investigated how AT may become informed, this paper sets out to investigate AT around earnings announcement events, when the probability that some market participants have access to private information is high (e.g., Ederington and Lee $(1993,1995))$. We test the hypothesis that algorithms are able to time their trades better than non-algorithmic traders around earnings announcements as a result of their advantage in

and was mistakenly believed to be reporting a new bankruptcy filing by the company. This caused the company's stock price to drop by 76 percent in just a few minutes before the NASDAQ halted trading. After the news had been identified as false, the stock price rebounded, but still ended the day 11.2 percent below the previous day's close." 
consistency and speed of execution. We investigate (a) the speed of price reaction, (b) trading patterns and trading profits, and (c) the lead lag relation between AT and non-AT traders volume imbalance (measured in 30 second intervals) during five minutes before and after earnings announcements.

We find that algorithms react significantly faster to information than non-algorithmic traders, for example cumulative returns for both good and bad news information events increase significantly for AT while there is no significant change for non-AT. During the 10 seconds post-earnings announcement that are positive surprises, the net buyer-initiated orderflow from AT is significantly higher while the increase in net buyer-initiated orderflow from non-AT is not significant. When the announcements are negative surprises the net seller-initiated orderflow from AT is higher, while the change in seller-initated orderflow from non-AT is not significant. Net buyer- initiated AT order flow reaches a maximum and is significantly correlated in the direction of the expected price movement between 30 and 90 seconds after good news announcement. AT generate increasing trading profits up to 90 seconds after announcements while non-AT generate losses during this time period. Finally our VAR systems of three equations also show that during pre-announcement period, nonAT volume imbalance leads AT volume imbalance, however, in the post announcement period, the direction of this lead is exactly reversed. Overall, our results suggest that compared with non-algorithmic traders, algorithms are faster at interpreting information correctly and hence, AT enhances market efficiency.

The remainder of the paper is organized as follows. Section 2 describes the data. Section 3 presents the methodology and an analysis of the empirical results. Section 4 reports the information shares contributed by AT versus non-AT during pre and post earnings announcements and Section 5 concludes the paper. 


\section{Data}

\subsection{Institutional setting}

The ASX is one of the world's top-10 listed exchange groups by market capitalization with a total market capitalization at $\mathrm{A} \$ 1.4$ trillion and over 2,183 companies listed in a wide array of industries as of the end of the investigated period in 2009. The Australian Securities Exchange is Australia's primary securities exchange. The major market index is the S\&P/ASX 200.

The ASX operates a fully automated continuous auction trading system where traders enter market or limit orders. Traders may enter, revise or cancel orders in the trading system from the pre-open phase commencing at 07:00; however, the trading system does not match orders until the market opens. An opening call auction algorithm starts at 10:00 and completes the opening procedure of all stocks by 10:10. Normal continuous trading follows the opening call auction and ends at 16:00. A closing call auction algorithm is run at 16:10 to establish the closing price of the day. The ASX displays its entire limit order book to both investors and brokers, while broker identities are anonymous pre- and post trade.

In accordance with the continuous disclosure regulation (in the ASX Listing rules 3.1 and complying with the Corporations Act) all listed companies must release price sensitive corporate announcements to the ASX as soon as they become aware of such information. Hence ASX is the only channel for listed companies to release corporate announcements. 
The trading halt policy of the ASX is governed by Chapter 17 of the ASX Listing rules ${ }^{4}$. The ASX rules set out that a trading halt may be imposed by the ASX, if the exchange receives or releases a company announcement which, in the opinion of the ASX, is market sensitive; or the company itself requests a trading halt from the exchange. If a trading halt is called, the concerned security is designated a pre-open status. Pre-open is the period before an opening call auction, during which orders may be placed but trades cannot be executed. The duration of trading halts are usually 1 hour for takeover announcements and 10 minutes for other announcements. The halted stock begins trading after the pre-open phase starting with an opening call auction that is aimed to maximize volume with minimum surplus (see ASX Market Rules, 2013 and Frino, Lecce and Segara, 2011).

\subsection{Sample selection and identification of algorithmic trades}

A unique dataset is obtained from the Australian Securities Exchange (ASX) for the period October 27, 2008 to October 23, 2009. The data include security, date, time (to the nearest millisecond), price, volume, and an indicator on whether the current trade is buyer- or sellerinitiated $^{5}$ for all equity transactions at the ASX. Important for this study, the dataset contains an indicator for whether the current trade is initiated by a computer algorithm, which enables us to precisely differentiate between electronic trades classified as AT and non-electronic trades classified as non-AT. ${ }^{6}$

\footnotetext{
${ }^{4}$ Refer to ASX Listing Rules, available at http://www.asx.com.au/regulation/rules/asx-listingrules.htm (Accessed on April 26, 2016).

${ }^{5}$ Trade initiation is classified based on information about whether a buy or a sell order caused the trade execution.

${ }^{6}$ Our data were generated from the original data tape recording the output directly from the central execution engine of the ASX, and contain all information about transactions and trading processes on the ASX equities markets. The ASX classifies each trading terminal that connects with the exchange execution engine into electronic or human terminals, depending on whether orders submitted from this terminal are generated automatically by a machine or entered by a human trader. There is one exception for retail traders that use online brokerage firms. In this case the ASX receives these retail
} 
Company announcements during the investigated period are obtained from Thompson Reuters Data Scope database. Normal ASX trading hours are from 10:00 am to 4:00 pm. ${ }^{7}$ In order to evaluate the trading behavior around the earnings announcements, we require the announcement time to fall between 11:10 am and 3:00 pm to allow at least one hour of continuous trading around the event. This selection process results in sample of 403 on market announcements by 265 companies. We further remove stock observations with less than 20 trades during a day, and companies not included in the S\&P ASX 200 index $^{8}$ from our sample. The final sample contains 166 earnings announcements by 101 different companies. If an information release is considered market sensitive the exchange imposes a trading halt around the information release, we analyze the trading leading up to and after the trading halt in the case of a trading halt and the trading leading up to and after the event in the case of no trading halt.

The call auction after the trading halt is designed to help market participants process the new information better and hence reduce excess price volatility; however, its effectiveness is questionable. For example, evidence provided by Lee, Ready, Seguin (1994), Corwin and Lipson (2000) and Christie, Corwin and Harris (2002) for the US markets, Kryzanowski, and Nemiroff (2001) for the Canadian markets, Kim, Yague and Yang (2008) for the Spanish markets and Frino et al. (2011) for the Australian markets unanimously suggests that spreads and volatility are higher after trading halts. This suggests that at the very least prices do not reach a new equilibrium immediately after the halt, which provides an ideal experimental

orders as machine generated. For our study, trading terminals of all major retail brokers are identified and re-classified as human terminals.

${ }^{7}$ The ASX follows a staggered opening process, where stocks are opened alphabetically in groups. The opening phase usually ends at 10:10 am after which all stocks are in the normal trading phase, until the market enters a pre-close phase at 4:00 pm.

${ }^{8}$ S\&P ASX200 companies are used because it has been shown that institutional traders (the main users of algorithms) are mainly focusing on large liquid stocks. For example Hendershott et al. (2011) show that AT improves liquidity particularly in large stocks. 
opportunity for us to examine the relative trading behavior of AT and non-AT in reaction to new information both for event with and without a trading halt.

Panel A of Table 1 presents daily statistics for number of trades, trade size and volume of AT initiated buy and sell trades, and Panel B of Table 1 reports daily statistics for number of trades, trade size and volume of non-AT initiated buy and sell trades. We observe three interesting patterns: (1) AT initiated trade size on both buy and sell side during announcement days are smaller than the trade size of non-AT initiated buy and sells trades. For example, the mean of trade size of AT initiated buys is about 7,378.58 which is only equal to $30 \%$ of non-AT initiated buys. This result confirm that AT often trade smaller size in order to minimize the price impact of their trades; (2) Number of algorithmic trades (trading frequency) in both buy and sells sides are much higher than number of non-AT. For instance, the mean of number of AT initiated sells is 843 and the mean of number of non-AT initiated sells is 196; and (3) On both the buy and sell side, AT-initiated volume is nearly twice larger than the non-AT initiated volume. These empirical results confirm that traders who use AT do this at high frequency with smaller trade size which generates larger trading volume around earnings announcements.

$<$ Insert Table 1 about here $>$

Table 2 presents descriptive statistics for the number of trades, trade size and volume in eight five minute time intervals during one hour pre and one hour post earnings announcements. The four five minute time intervals before the announcements are $(-20,-15)$, $(-15,-10),(-10,-5)$ and $(-5,0)$ and the four five minute time intervals after the announcements are: $(0,5),(5,10),(10,15)$ and $(15,20)$ non overlapping minutes in relation to the earnings release. Panel A and Panel B presents descriptive statistics for AT and non-AT initiated buy trades one hour before earning announcements. Panel C and Panel D present 
descriptive statistics for AT and non-AT initiated sell trades one hour after earnings announcements. The third column of Panels A to D report the differences in means and medians of the descriptive statistics between AT and Non-AT for each time intervals. We find most of these differences are statistically significant at $1 \%$ percent. ${ }^{9}$ The direction is determined by the quote rule and all results are reported separately for buy initiated trades and sell initiated trades. Several interesting results emerge in Table 2. For buy trades, AT initiated trading volume decreases from $478,490.17$ in the $(-20,-15)$ time interval to $250,325.08$ in the $(-5,0)$ time interval. AT initiated volume then increases to $884,689.99$ in the $(0,5)$ time interval and again decreases to $596,459.52$ in the $(15,20)$ time interval. This pre and post AT volume behavior on the buy side is consistent with the hypothesis that discretionary liquidity traders will decrease their trading volume as time draws closer to the announcement, as they are concerned with the increase in adverse selection component in their trading cost due to increased information asymmetry. In consequence they increase their trading immediately after the earnings announcement, as the adverse information cost is reduced due to the release of information. (see Chae (2005) and George et.al (1994)).

We find the volume initiated by AT on the sell side during pre and post announcements is very similarly distributed to the buy trading volume initiated by AT. As earnings releases typically trigger AT activity in one direction, buyer-initiated volume is dominated by AT activity during positive surprises and seller-initiated volume is dominated by AT activity during negative surprises.

Non-AT initiated buy volume on the other hand increases from $413,610.56$ in the $(-20$, $15)$ to $529,885.48$ in the $(-5,0)$ time interval. Non-AT volume falls in the first five minute interval after the announcement $(0,5)$ to $292,841.16$ and increases to $817,227.65$ in the

\footnotetext{
${ }^{9}$ Kruskal-Wallis and Wilcoxon signed rank tests are used to test the differences in mean and median between AT and non-AT descriptive statistics (i.e. the number of trades, trade size and trading volume) respectively.
} 
second five minute interval. We find the lowest buy volume initiated by non-AT is $413,610.56$ in the $(-20,-15)$ interval pre announcement and the largest buy volume is $975,753.66$ in the $(15,20)$ interval after the announcement. These results confirm that the AT initiated buy volume distribution is systematically different from the buy volume initiated by non-AT during one hour before and the hour after announcements and that the largest number of trades initiated by AT occurs in the first five minutes and that the largest number of trades initiated by non-AT occurs in the fourth five minutes interval after the earnings release. Hence the trading frequency of AT increases immediately after information release indicating that AT participants process information quickly and exhibit faster speed of execution in comparison to non-AT participants.

$<$ Insert Table 2 about here $>$

\subsection{Classification of announcements as good news or bad news}

We classify observations into a subset of good news announcement if the forecasting error of announcement is equal or above one standard deviation from the mean of the forecasting error (Actual Earnings Per Share (EPS) - Median Forecast EPS) distribution. An observation is classified into bad news subset if the forecasting error of the announcement is equal or below one standard deviation from the mean of the forecasting error distribution. The analysts' earnings forecasts and actual earnings data are sourced from the Institutional Brokers Estimate System (IBES). Cross-section of market participants data are recorded to collect their forecasts regarding the following week's earnings announcements. The median of collected forecasts serves as an estimate for the market expectations of the upcoming releases. We collect quarterly actual earnings and median earnings forecasts and calculate a standardized surprise as follows: 


$$
\text { Surprise }=\frac{\text { Actual EPS - Median Forecast EPS }}{\text { Standard deviation [Actual EPS - Median Forecast EPS] }}
$$

By using the one standard deviation criteria we focus on announcements that are either significantly positive or negative surprises compared to the mean of the forecasting error (Actual EPS - Median Forecast EPS) distribution. Although the normal practice is to use observations that fall outside two standard deviations, we employ one standard deviation in order to retain as many observations as possible in our sample, while still focusing on significant deviations from the forecasted EPS. If the surprise ratio is greater than one standard deviation we classify news as good news, if the surprise ratio is less than one standard deviation we classify the news as bad news. From 122 announcements, 66 announcements are classified as good news and 56 are classified as bad news.

\section{Empirical Results}

The empirical results section consists of three subsections. In first section, we examine the speed of price reaction of AT versus non-AT to good news and bad news in a five minute event-window centered at the earnings announcement. In the second section, we investigate trading patterns (measured by order flow $^{10}$ ) and trading profit during before and after announcements in order to determine whether algorithmic traders are able to time their trades better than non-algorithmic traders. In the third section we use three equations of a vector autoregressive system to examine the temporal relation between trading activity (measured by volume imbalance ${ }^{11}$ ) of AT, non-AT and market returns before and after earnings announcements.

\footnotetext{
${ }^{10}$ Order flow is measured as number of buys minus number of sells.

${ }^{11}$ Volume imbalance is measured as buy volume minus sell volume. We control for firm differences with a market capitalization control and firm fixed effects.
} 


\subsection{The Speed of price reaction to earnings announcements}

To examine the speed of the reaction to news, cumulative average returns (CARs) and cumulative adjusted average returns (CAARs) are calculated in a five minute event-window centered at the earnings announcement. We investigate the CARs and CAARs separately for good and bad news announcements to check for asymmetry in the price response.

We define an event window starting at $-\tau$ and ending at $\tau$, where the window covers the period -5 minutes to 5 minutes around the earnings announcement and return is calculated each ten second interval. Hence $-\tau=-30$ and $\tau=30$.

We first compute the $\mathrm{R}_{\mathrm{i}, \mathrm{j}, \mathrm{k}}$ return for $\mathrm{i}$ th firm, $\mathrm{j}$ th time position in the window $[-\tau, \tau]$ and kth announcements. In the next step, we compute $\bar{R}_{i, j}$ average return for ith firm over the number of $\mathrm{N}_{\mathrm{h}}$ announcements where $\mathrm{h}=1$ for the good news and 2 for bad news.

$$
\bar{R}_{i, j}=1 / N_{h} \sum_{k=1}^{N_{h}} R_{i, j, k}
$$

In the third step, we aggregate the average return cross-sectionally $\bar{R}_{i, j}$ for all firms in the sample becomes

$$
\overline{A R}_{j}=1 / m_{h} \sum_{i=1}^{m_{h}} \bar{R}_{i, j}
$$

The cumulative average return at time $\tau_{k} \in[-30,30]$ is

$$
\overline{\operatorname{CAR}}_{(-30,30)}=\sum_{j=-30}^{\tau_{k}} \overline{A R}_{j}
$$


We use the same procedure to calculate cumulative average abnormal returns. The only difference is that we calculate abnormal return for ith firm, $\mathrm{j}$ th time and $\mathrm{k}$ th announcement is to replace $R_{i, j, k}$ return by

$$
A R_{i, j, k}=R_{i, j, k}-\overline{\bar{R}}_{j, k}
$$

where $\overline{\bar{R}}_{j, k}$ is the return of the ASX 200 index on jth time point and $\mathrm{k}$ th announcements. The cumulative average abnormal return is:

$$
\overline{\operatorname{CAAR}}_{(-30,30)}=\sum_{j=-30}^{\tau_{k}} \overline{A A R_{j}}
$$

where $\overline{A A R}_{j}$ is average abnormal returns at the $\mathrm{j}^{\text {th }}$ time point and $\tau_{k} \in[-30,30]$.

If the cumulative adjusted average returns (CAARs) are positive it suggests that the sample outperformed the index during earning announcements; if the CAARs are negative it means that the sample underperforms the index during earning announcements.

Figure $1 \mathrm{a}$ and $1 \mathrm{~b}$ present the cumulative average returns [CARs] and cumulative average adjusted returns [CAARs] in a Five minute event-window centered at the earnings announcement. To check for asymmetry in the price response, CARs are examined separately for good and bad news announcements. During the pre-earnings announcements period, CARs for AT and non-AT appear to be relatively flat when compared to cumulative average returns post-earnings announcement. CARs for AT associated with good news peak at 150-30 0 seconds after the announcement and do no longer increase 300 seconds after the event. The CARs for AT associated with bad news decrease immediately after the announcement bottoming out 100 seconds after the announcement. Cumulative average returns associated with bad news hence appear to react faster than good news. CARs for non-AT do not reveal any apparent differences pre- and post- earnings announcement. CAARs exhibit similar results to the ones reported for CARs, also indicating a slower reaction by AT to good news 
compared to bad news. The effect of good news appears to carry on beyond the 300 seconds after the announcement Overall these results suggest that the initial price reaction for AT is faster than the price reactions for non-AT.

$<$ Insert Figure 1a and $1 \mathrm{~b}$ about here $>$

\subsection{Trading patterns and estimated trading profits}

We examine whether AT have the ability to time their trades better than non-AT ${ }^{12}$. The order flows are calculated as the number of trades bought minus the number of trades sold. A positive order flow suggests that more than half of all trades traded in that interval by the specific trader type were bought. Similarly, a negative order flow suggests that the specific trader type tended to be on the sell side in that particular time interval. More specifically, we examine whether algorithmic traders are able to trade in the same direction as prices are expected to move, based on the classification of good or bad news.

Erenburg et al (2006) points out that a positive (negative) order flow for good news (bad news) may be driven, at least in part, simply by the AT causing the price change and not due to their correctly predicting price changes. To ensure the robustness of the results and to test whether the trading strategy followed by algorithmic traders is profitable we calculate trading profit before and after announcements.

\footnotetext{
${ }^{12}$ Erenburg et.al (2006) examine order flows patterns to detect whether market makers have the ability to time their trades better than other traders in trading S\&P 500 index futures and E-mini 500 index futures.
} 
We define trading profit for a trade at time $t$ as follows:

$$
\text { Profit }_{t}=D_{t}\left(R P_{t}-P_{t}\right) Q_{t}
$$

where $R P_{t}$ is the reference price, $P_{t}$ is the trade price, $D_{t}$ is an indicator variable equal to one for buys and minus one for sells, $Q_{t}$ is the trade size ${ }^{13}$. The reference price is calculated as the average trade price during the sixth minute after the announcement. We use price as the benchmark because based on order flow results the trading strategy used by algorithmic traders after the announcement appears to be very short-term.

In this section the order flow and trading profit are examined to determine the ability of AT and non-AT to time their trades. More specifically, to examine whether AT and non-AT are able to trade in the same direction as prices are expected to move, based on the classification of the earnings announcements as good or bad news.

Table 3 reports the order flows of AT and non-AT pre- and post- earnings announcement. Statistically significant results are identified using two-tailed test. Post-earnings announcements, AT order flow associated with good news show a significant order flow at $1 \%$ level during the first 10 seconds and AT order flow associated with bad news show significant results for the periods 0 to 10 and 10 to 20 seconds with a significance level of 5\% and $10 \%$ respectively. Order flow for AT associated with good news reaches a maximum and significant order flow at $1 \%$ level in the direction of the expected price movement between 30 and 60 seconds after the announcement. This can be interpreted that AT are net buyers immediately after the good news announcements and net sellers immediately after the bad news announcements. The order flow pattern is less pronounced for non-AT, where most of the order flows are not statistically significant.

\footnotetext{
${ }^{13}$ We follow Erenburg et.al (2006) to calculate trading profits for each trade in each examined time interval after the announcement. Chakravarty and Li (2003) use a similar approach to estimate trading profits in futures markets.
} 
$<$ Insert Table 3 about here $>$

Figure 2 shows the volume imbalance that is calculated as buy volume - sell volume for AT and non-AT in a five minute event-window centered at the earnings announcement. The event time (earnings announcement time) is defined as time 0 . The AT volume imbalance associated with good news and bad news are relatively flat pre-earnings announcement. Postearnings announcement AT volume imbalance associated with good news increases immediately after the announcement and reaches a maximum by approximately 90 seconds. It takes about 5 minutes for volume imbalance to return to normal levels. Volume imbalance for AT associated with bad news decreases shortly before earnings announcement and sharply decreases immediately after the announcement. Non-AT volume imbalance for good (bad) news increases (decreases) accordingly but to a less extent than that of AT.

$<$ Insert Figure 2 about here $>$

Table 4 reports trading profits pre- and post- earnings announcement. These profits are the average profit per trade and hence the economic significance in the aggregate is significant. Consistent with order flow, the cumulative profit for AT reverts from negative to positive around 30 seconds after the announcement. AT profit increases most up to 90 seconds after the announcement and remains positive but starts to decline after 90 seconds post. The cumulative non-AT profit is increasingly negative leading up to the announcement and remains negative. This can be interpreted as evidence that AT incorporate new information faster than non-AT. Therefore, during the post announcement period, transactions by AT are more informative than non-AT. These results are consistent with Hendershott et al. (2011) who find that AT enhance the informativeness of quotes.

$<$ Insert Table 4 about here $>$ 


\subsection{The temporal relation between AT and non-AT trades and market returns.}

This section examines the temporal relation of AT and Non-AT volume balance and returns using Vector autoregressions (VAR) during one hour around earning announcements. The VAR is a system of three equations in which lags of returns, AT volume imbalance and nonAT volume imbalance are used to explain each other. We use invPrice $_{i, t}$ (the inverse stock price) and $\log \mathrm{MCap}_{i, t}$ (the log of market capitalization ) as additional control variables in each of three equations. Our VAR system of three equations pooling cross-sectional and time series data in a fixed effects model is specified as follows.

$$
\begin{aligned}
& \text { return }_{i, t}=\alpha_{0}+\chi_{1} D_{\text {pre }}+\varphi_{1} D_{\text {post }}+\sum_{j=1}^{5} \gamma_{1, j} \text { return }_{t-j} * D_{\text {pre }}+\sum_{j=1}^{5} \delta_{1, j} \text { algo }_{t-j} * D_{\text {pre }}+\sum_{j=1}^{5} \omega_{1, j} \text { nonAlgo }_{t-j} * D_{\text {pre }}+ \\
& \sum_{j=1}^{5} \varsigma_{1, j} \text { return }_{t-j} * D_{\text {post }}+\sum_{j=1}^{5} \sigma_{1, j} \text { algo }_{t-j} * D_{\text {post }}+\sum_{j=1}^{5} \gamma_{1, j} \text { nonAlgo }_{t-j} * D_{\text {post }}+\sum_{j=1}^{5} \pi_{1, j} \text { return }_{i, t-j}+\sum_{j=1}^{5} \beta_{1, j} \text { algo }_{i, t-j}+ \\
& \sum_{j=1}^{5} \lambda_{1, j} \text { nonAlgo }_{k-j}+\sum_{i=1}^{74} \rho_{1, i} d_{i, t}+\psi_{1, \text { inverc }} \text { invPrice }_{i, t}+\psi_{1, \text { logMcap }}{\log M C a p_{i, t}}_{1, i, t}
\end{aligned}
$$

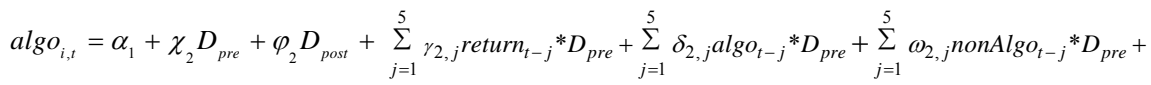

$$
\begin{aligned}
& \sum_{j=1}^{5} \varsigma_{2, j} \text { return }_{t-j} * D_{\text {post }}+\sum_{j=1}^{5} \sigma_{2, j} \text { algo } t-j^{*} D_{\text {post }}+\sum_{j=1}^{5} \gamma_{2, j} \text { nonAlgo }_{t-j} * D_{\text {post }}+\sum_{j=1}^{5} \pi_{2, j} \text { Return }_{i, t-j}+\sum_{j=1}^{5} \beta_{2, j} a \text { lgo }_{i, t-j}+ \\
& \sum_{j=1}^{5} \lambda_{2, j} \text { nonAlgo }_{k-j}+\sum_{i=1}^{74} \rho_{2, i} d_{i, t}+\psi_{2, \text { invPrc }} \text { invPrice }_{i, t}+\psi_{2, \log M C a p} \log M C a p_{i, t}+\varepsilon_{2, i, t} \\
& \text { nonAlgo }_{i, t}=\alpha_{2}+\chi_{3} D_{\text {pre }}+\varphi_{3} D_{\text {post }}+\sum_{j=1}^{5} \gamma_{3, j} \text { return } t-j D_{\text {pre }}+\sum_{j=1}^{5} \delta_{3, j} \text { algo }_{t-j} * D_{\text {pre }}+\sum_{j=1}^{5} \omega_{3, j} \text { nonAlgo } t-j \\
& \sum_{j=1}^{5} \varsigma_{3, j} \text { return }_{t-j} * D_{\text {post }}+\sum_{j=1}^{5} \sigma_{3, j} \text { algo }_{t-j} * D_{\text {post }}+\sum_{j=1}^{5} \gamma_{3, j} \text { nonAlgo }_{t-j} * D_{\text {post }}+\sum_{j=1}^{5} \pi_{3, j} \text { Return }_{i, t-j}+\sum_{j=1}^{5} \beta_{3, j} \text { algo }_{i, t-j}+ \\
& \sum_{j=1}^{5} \lambda_{3, j} \text { nonAlgo }_{k-j}+\sum_{i=1}^{74} \rho_{3, i} d_{i, t}+\psi_{3, \text { invPrc }} \text { invPrice }_{i, t}+\psi_{3, \log M \text { Cap }} \log M \text { Cap }_{i, t}+\varepsilon_{3, i, t}
\end{aligned}
$$

where $\operatorname{algo}_{i, t}$ is the 30 second imbalance for AT and nonAlgo $i, t$ is the 30 second imbalance for non-AT for company $i$ at time $t$. Imbalance is calculated as buy volume - sell volume. return $_{i, t}$ is the 30 second return. $D_{\text {pre }}$ is a dummy variable that equals 1 for the first 300 seconds before the announcement and $D_{\text {post }}$ is a dummy variable that equals 1 for the first 300 
seconds after the announcement. ${ }^{14}$ We use $D_{\text {pre }}$ and $D_{\text {post }}$ dummy variables to create interaction terms with explanatory variables to model and test the effects of five minutes pre and post of earning announcements on temporal relation between returns, algo and non algo volume imbalance (buy minus sell volume) with the their bench mark time period ( i.e. twenty five minutes before and after the first five minutes pre and after earning announcements) ${ }^{15} d_{i, t}$ is a dummy variable for each company used in our fixed effects model. invPrice $_{i, t}$ denotes the inverse price and $\operatorname{logMCap}{ }_{i, t}$ is the $\log$ of market capitalization. An Fstatistic is used to test the null hypothesis that all company dummy variables are equal and the test results are reported in the last row of the Panel E of the Table 5.

Our volume imbalance measure is simply the buy volume minus the sell volume in each stock, time interval, as opposed to the OIB\# and OIB $\$$ used by Chordia et.al $(2005,2008)$ for example, who scale the imbalance by the total number of trades and dollar value traded. As we analyze data of high frequency, we do not find it suitable to scale the imbalance measure with a static denominator such as total period volume, which is expected to vary more between stocks than over time within stocks. Instead, the firm level market capitalization and the firm fixed effects in our model control for differences in trading activity and other unobserved heterogeneity across groups (Gormley and Matsa, 2013). Another advantage of our approach is that we are able to identify the effect of order imbalance separately from the impact of price changes.

\footnotetext{
${ }^{14}$ As a robustness test a GMM model is estimated using 10 second returns and volume imbalance with a dummy variable indicating pre and post announcements. The results are very similar to our results reported in Table 5 .

15 We use a deterministic time varying coefficient model for each equation, to test and model the effects of earnings announcements on the intercept and coefficients of explanatory variables of five minutes pre and post announcement with the coefficients of corresponding variables in the benchmark time period.
} 
We use OLS to estimate the parameters in Equation 8,9 and 10. The Newey and West procedure (1987) is used to calculate consistent standard errors of regression parameter estimates under a serially correlated and heteroskedastic error process.

Table 5 presents empirical results on the temporal relation between AT volume imbalance, non-AT volume imbalance and returns during half hour before and after earning announcements. In panel A, we find that the coefficients of the dummy variable of pre five minute announcements are not statistically significant. These results indicate that preearnings announcements do not cause a significant impact on intercepts of returns, AT and non-AT imbalance. The coefficients of the dummy variables representing five minutes postearnings announcements are positive and significant for the intercepts of the returns and the AT imbalance equations, but not significant for the Non-AT equations. These results suggest that AT activity increases in the five minutes post-earnings announcement. The coefficient of the dummy variable $\mathrm{D}_{\text {post }}$ in the Non-AT equation is positive but not significant, which can be interpreted as an indications that information leakage is not severe during the preannouncement period, and that the market reflects new information during the post-earnings announcement period.

Panel B presents the lag relation between return, AT and non-AT imbalance during five minute pre-earnings announcement. In the return equation, the first lag coefficient of Algo $* D_{\text {pre }}$ is positive and significant and the first three lag coefficients of nonAlgo* $D_{\text {pre }}$ are positive and significant. This reveals that both AT and non-AT have positive impact on returns during first five minutes pre-earnings announcement. In the AT (Algo) equation, the coefficient of return $\mathrm{t}_{\mathrm{t}-1} * \mathrm{D}_{\text {pre }}$ is positive and significant and the first three lag coefficients of nonAlgo $* \mathrm{D}_{\text {pre }}$ are also positive and significant. In the non-AT equation, the coefficient of return $_{\mathrm{t}-1} * \mathrm{D}_{\text {pre }}$ is positive and significant and none of the the five lag coefficients of algo* $\mathrm{D}_{\text {pre }}$ 
are significant. These results suggest that both AT and non-AT follow a trend chasing strategy in the short horizon. The observation that AT do not affect non-AT before the announcement and non-AT leads AT, can be interpreted as an indication that non-AT are more informed than AT pre-earnings announcements.

Panel $\mathrm{C}$ presents the lagged association between return, AT and non-AT imbalance during the five minutes post-earnings announcement. In the return equation, the first three lag coefficients of algo $* \mathrm{D}_{\text {post }}$ are positive and significant and the coefficient of nonAlog $\log _{\mathrm{t}-1} * \mathrm{D}_{\text {post }}$ is positive and significant. This suggests that AT have a stronger impact on returns in the post-announcement period than in pre-announcement period. In the AT equation, we find that the coefficient of return $\mathrm{t}_{-1} * \mathrm{D}_{\text {post }}$ is positive and significant and none of the lagged coefficients of nonAlgo* $\mathrm{D}_{\text {post }}$ are significant. In the non-AT equation, none of the lag coefficient of return* $\mathrm{D}_{\text {post }}$ are significant. Interestingly we observe that the first two algo* $\mathrm{D}_{\text {post }}$ are positive and highly significant. These results suggest that AT strongly leads non-AT while non-AT has no impact on AT in the five minute post-announcements period. This evidence indicates that AT is able to process information more efficiently and independently of Non-AT.

Panel D presents the temporal relation between returns, AT and Non-AT volume imbalance during the normal time period not impacted by the announcement (i.e. our bench mark period is twenty five minutes before and after the first five minute pre- and post period of earning announcements). We find that the first lagged coefficient of AT is positive and significant in the return equation. There is no significant lead and lag association between AT and Non -AT volume imbalance during this period. Empirical results show that all three variables have a strong auto-correlation structure. 
Panel E presents the empirical results of control variables in each equation. All Fstatistics, reported in Panel E are significant at one percent level. These results suggest that we reject the null hypothesis that all company dummy variables are equal (i.e. there is a significant difference between the means in each equation).

Comparing our results in section 3.2 where we examine order flow measured as the number of buys minus the number of sells, to the results this section where we analyze volume of buys minus volume of sells, we find that the results are consistent in that the direction of AT changes swiftly in the same direction of an earnings surprise. Based on the results in Section 3.2 which directly assesses the profitability of AT, each trade by an algorithmic trader earns an average profit of over $\$ 6,000$ per earnings release during the 160 seconds after the announcement, while non-AT makes a loss during the same period (see Table 4). Such short term profits translate into highly significant returns of economics significance in the long run.

$<$ Insert Table 5 about here $>$

\section{Robustness test: Information shares pre and post earnings announcements}

As a robustness test we use methodology from Hasbrouck (2002) to calculate information share ratios, 30 minutes before and 30 minutes after earnings announcements. We use the following vector error correction model (VECM):

$$
\Delta p_{t}=\gamma \alpha^{\prime} p_{t-1}+\sum_{i=1}^{k} A_{i} \Delta p_{t-i}+\varepsilon_{t}
$$

where $p_{t}$ is an vector of cointegrated prices, $A_{l}$ are $n \times n$ matrices of autoregressive coefficients, $k$ is the number of lags, $\alpha^{\prime} p_{t-1}$ is an $(n-1) \times 1$ vector of error correction terms, $\gamma$ 
is an $(n-1) \times 1$ matrix of adjustment coefficients, and $\varepsilon_{t}$ is an $n \times 1$ vector of price innovations. The VECM is estimated using log-prices and ten lags.

The error correction term for the pricing association between AT and non-AT is $\alpha^{\prime} p_{t-1}=p_{t-1}^{A T}-p_{t-1}^{n o n-A T}$. Therefore the coefficients $\gamma$ of the error correction term measure the price reaction to the deviation of the price difference between the two markets from zero. The greater the coefficient, the more the particular market reacts to deviations from equilibrium.

Hasbrouck shows that the following vector moving average (VMA) model can be derived from the VECM :

$$
\Delta p_{t}=\Psi(L) \varepsilon_{t}
$$

where $\Psi(L)$ is a polynomial in the lag operator. The VMA coefficients can be used to calculate the variance of the underlying efficient price:

$$
\sigma_{u}^{2}=\Psi \Omega \Psi^{\prime}
$$

where $\Psi$ is a row vector composed of VMA coefficients and $\Omega=\operatorname{var}\left(\varepsilon_{t}\right)$. After transforming $\Omega$ into a lower triangular matrix $F$ by the Cholesky factorization, $\Omega=F F^{\prime}$, it is possible to calculate the information share of the market $j$ as:

$$
I_{t}=\frac{(\Psi F)_{j}^{2}}{\sigma_{u}^{2}}
$$

where $(\Psi F)_{j}$ is the $j$ th element of the row matrix $\Psi F$. This model produces estimates of the upper (lower) bound of the information share for the first (last) variable in the factorization. 
Similar to Hasbrouck (2002) we calculate price discovery for each day separately and then average the resulting information shares across days. Several consecutive trades at the same price are removed. As the input data for the VECM analysis we use matched time series with one-second intervals between observations. If there is no price reported at a particular second, the previous available price is used. If there are several trades reported with the same timestamp, only the last trade price is used.

The results of the calculation of information shares are shown in Table 5. The average midpoint of the upper and lower bounds of the information share ratio 30 minutes prior earnings announcement for AT and non-AT is $42.29 \%$ and $57.71 \%$ respectively. Whereas 30 minutes post-earnings announcement AT increases to $65.61 \%$ and non-AT decreases to $34.42 \%$. These results suggest that non-AT make a dominant contribution to price discovery 30 minutes before the earnings announcement while AT make a dominant contribution to price discovery 30 minutes after the earnings announcement. ${ }^{16}$

$<$ Insert Table 6 about here $>$

\section{Conclusions}

This paper examines if algorithmic trading activity contributes to the information content of stock prices in the period surrounding corporate earnings announcements. We use a unique data set from the Australian Securities Exchange, which allows us to identify trading activity and direction of AT versus non-AT before and after public information releases, to determine

\footnotetext{
${ }^{16}$ Yan and Zivot (2010) demonstrate that the information share measures a combination of speed of impounding information and relative avoidance of noise. When the levels of noise differ greatly relative to the variation in the speed of information incorporation, the information share measure can lead to erroneous conclusions. Yan and Zivot (2010) suggest an information leadership metric, which according to simulation results by Putniņš (2013) correctly assign contributions to price discovery when noise levels differ in a bivariate system. In Appendix, we calculate and compare the information leadership for AT and non-AT trades, and our results are robust to this alternative measure.
} 
if AT react more rapidly to information and employ profitable trading strategies in comparison with non-AT. We consider the following conclusions and contributions as important.

(1) CARs and CAARs over a five minute event-window centered at each earnings announcement show that during the pre-earnings announcements period, CARs for AT and non-AT are insignificant when compared to cumulative average returns post-earnings announcements. CARs for AT associated with good news peak at 150-300 seconds after the announcement, and do no longer increase 300 seconds after the event. The CARs for AT associated with bad news decrease immediately after the announcement, bottoming out 100 seconds after the announcement. This suggests that the initial price reaction for AT is faster than the price reactions for non-AT. CAARs exhibit similar results as those reported for CARs.

(2) An order flow analysis show that AT are net buyers immediately after the good news announcements and net sellers immediately after the bad news announcements, whilst nonAT reveals no significant results pre and post earnings announcements. The AT volume imbalance associated with good news and bad news is relatively neutral pre earnings announcements. Post earnings announcement AT volume imbalance associated with good news increases immediately after the announcement and reaches a maximum by approximately 90 seconds. Volume imbalance for AT associated with bad news decreases shortly before earnings announcement and sharply decreases immediately after the announcement. Non-AT volume imbalance for good and bad news increase and decrease accordingly but to a lesser extent than for AT. These results provide evidence that AT exhibit faster speed of execution to incorporate new information than non-AT. 
(3) We report trading profits for AT and non-AT pre- and post- earnings announcements. Consistent with the order flow analysis, the cumulative profit for AT reverts from negative to positive around 30 seconds after the announcement. Cumulative AT profits increase up to 90 seconds after the announcement, and remain positive but declines after 90 seconds post. The cumulative non-AT profits are increasingly negative leading up to the announcement and remain negative. This can be interpreted as evidence that AT incorporate new information faster than non-AT.

(4) Our VAR system of three equations provides several interesting results: First, during the pre-announcement period, non-AT volume imbalance leads AT volume imbalance, however, in the post announcement period, the direction of this lead-lag association is exactly reversed. This result suggests that information leakage is not severe preannouncement and that the market reflects new information during the post earnings announcement period. AT volume imbalance increases in the post earnings announcement period, while non-AT volume imbalance is not significantly different between the pre and post earnings announcement periods. Second, both AT and Non-AT activity predict positive market returns. Third, both the first and the second lag of market return are positively related to AT activity in both the pre- and the post-announcement periods, this result confirms that, in the aggregate, the net AT activity follows a momentum trading strategy around earnings announcements.

(5) We find that the average information share of non-AT is larger than the average information share of AT pre- earnings announcement and the results is exactly reversed post announcement. These results are consistent with the results of our VAR analysis in point (4), that non-AT activity lead AT activity before announcements, and that the results is reversed that AT activity lead non-AT after announcement periods. 
In summary, we provide new empirical evidence to suggest that computer programs submitting AT have the ability to process information faster than non-AT and benefit from fast trade execution during information release periods. Consequently, AT earn higher profits than non-AT because they have better market timing ability than non-AT. Our results suggest that AT improve market efficiency. Regulators and the public need to realize that algorithms make markets more efficient and are compensated for this. Hence regulation of algorithmic trading should deal with potential effects of fast disappearing liquidity (flash crashes/spikes), but it is important to note that these negative effects are offset by faster price discovery.

\section{References}

Baillie, R. T., G. Booth, Y. Tse, Y. and T. Zabotina, 2002, Price discovery and common factor models', Journal of Financial Markets, 5, 309-321.

Bernard, V. L. and J., K. Thomas, 1989, Post-Earnings-Announcement-Drift, Journal of Accounting Research, 27, 1-36.

Biais, B., T. Foucault, and S. Moinas. "Equilibrium fast trading." Journal of Financial Economics 116.2 (2015): 292-313.

Brogaard J. A., T. Hendershott and R. Riordan, 2014, High Frequency Trading and Price Discovery, Review of Financial Studies, 27, 2267-2306.

Brogaard, J. A., 2010, High frequency trading and its impact on market quality, Working Paper. Kellogg School of Management, Northwestern University, School of Law.

Campbell J. Y., T. Ramadorai, and A. Schwartz, 2009, Caught on tape: Institutional trading, stock returns, and earnings announcements, Journal of Financial Economics, 92, 66-91.

Carvalho, C., N. Klagge and E. Moench, 2011, How Well Do Financial Markets Separate News from Noise? Evidence from an Internet Blooper, Available from:

Chae, J., 2005, Trading volume, information asymmetry, and timing information. Journal of Finance, 60, 413-442.

Chordia T., R. Roll and A. Subrahmanyam, 2005, Evidence on the speed of convergence to market efficiency, Journal of Financial Economics, 76, 271-292

Chordia T., R. Roll and A. Subrahmanyam, 2008, Liquidity and market efficiency, Journal of Financial Economics, 87, 249-268. 
Christie, G.W., Corwin, A.S., Harris, H.J., 2002. Nasdaq trading halts: The impact of market mechanisms on prices, trading activity, and execution costs. The Journal of Finance, 57, $1443-1478$.

Corwin, A.S., Lipson, L.M., 2000. Order flow and liquidity around NYSE trading halts. The Journal of Finance, 55, 1771-1801.

Ederington, L. H., J. H. Lee, 1993, How markets process information: News releases and volatility, Journal of Finance, 48, 1161-1191.

Ederington, L. H., J. H. Lee, 1995, The short-run dynamics of the price adjustment to new information, Journal of Financial and Quantitative Analysis, 30, 117-134.

Erenburg, G., A. Kurov, D. J. Lasser, 2006, Trading around macroeconomic announcements: Are all traders created equal? Journal of Financial Intermediation, 15, 470-493.

Fleming, M. J., E. M. Remolona, 1999. Price formation and liquidity in the US Treasury market: The response to public information, Journal of Finance, 54, 1901-1915.

French, K. and R. Roll, 1986. Stock return variances: The arrival of information and the reaction of traders. Journal of Financial Economics, 17, 5-26.

Frino, A., S. Lecce and R. Segara, 2011, The impact of trading halts on liquidity and price volatility: Evidence from the Australian Stock Exchange, Pacific-Basin Finance Journal, 19, 289-307.

George, T. J., K. Gautam and N. Mahendrarajah, 1994, Trading volume and transaction costs in specialist markets, Journal of Finance, 49, 1489-1505.

Gonzalo, J. and C. Granger, 1995, Estimation of common long-memory components in cointegrated systems, Journal of Business \& Economic Statistics, 13, 27-35.

Gormley, T. A. and D. A. Matsa, 2014, Common errors: How to (and not to) control for unobserved heterogeneity, Review of Financial Studies, 27, 617-661.

Grossman, S.J. and J. E. Stiglitz, 1980, On the Impossibility of Informationally Efficient Markets, American Economic Review, 70, 393-408.

Harris, L., 2003, Trading and Exchanges: Market Microstructure for Practitioners, Oxford University Press.

Hasbrouck, J. 1995, One security, many markets: Determining the contributions to price discovery, Journal of Finance, 50, 1175-1199.

Hasbrouck, J., 2002. Stalking the efficient price in market microstructure specifications: an overview,1 Journal of Financial Markets, 5, 329-339

Hasbrouck, J., G. Saar, 2009. Technology and liquidity provision: The blurring of traditional definitions, Journal of Financial Markets, 12, 143-172. 
Hendershott, T. and R. Riordan, 2011, Algorithmic Trading and Information, Working Paper Haas School of Business, University of California at Berkeley.

Hendershott, T., C. Jones and A. Menkveld, 2011, Does algorithmic trading improve liquidity? Journal of Finance, 66, 1-33.

http://libertystreeteconomics.newyorkfed.org/2011/10/how-well-do-financial-markets-separate-newsfrom-noise-evidence-from-an-internet-blooper.html, [Accessed 15 October 2012].

Kim, Y.H., Yague, J., Yang, J.J., 2008. Relative performance of trading halts and price limits: Evidence from the Spanish Stock Exchange. International Review of Economics and Finance 17, 197-215.

Kirilenko, A., Albert S. Kyle., M. Samadi and T. Tuzun, 2011, The Flash Crash: The Impact of High Frequency Trading on an Electronic Market, University of Maryland, Working Paper.

Kryzanowski, L., H. Nemiroff, 2001, Market quote and spread component cost behavior around trading halts for stocks interlisted on the Montreal and Toronto Stock Exchanges. Financial Review, 36, 115-138.

Kyle, A. S., 1985, Continuous Auctions and Insider Trading, Econometrica, 53, 1315-1335.

Lee, C. M. C., M. J. Ready, and P. J. Seguin, 1994, Volume, volatility, and New York Stock Exchange trading halts, Journal of Finance, 49, 183-214.

Newey, W., West, K., 1987. Hypothesis testing with efficient method of moments estimation. International Economic Review, 28, 777-787.

Putniņš, T. J., 2013, What do price discovery metrics really measure? Journal of Empirical Finance, 23, 68-83.

Yan, B. and E. Zivot, 2010, A structural analysis of price discovery measures, Journal of Financial Markets, 13, 1-19. 


\section{Appendix}

The Information Leadership Share (ILS) developed in Yan and Zivot (2010) and Putniņš (2013) is a combination of two established measures in the price discovery literature, i.e. the Hasbrouck (1995) Information Share (IS) and the Gonzalo and Granger (1995) Component Share (CS). Both IS and CS decompose price innovations into permanent and temporary components, which measure the incorporation of new information and the relative level of noise in the price series.

In particular, Putniņš (2013) estimates the IS and CS metrics using the Vector Error Correction Model (VECM) parameters and variance covariance of the error terms as in Baillie et al. (2002).

$\Delta p_{1, t=} \alpha_{1}\left(p_{1, t-1}-p_{2, t-1)}+\sum_{i=1}^{200} \gamma_{i} p_{1, t-i}+\sum_{j=1}^{200} \gamma_{j} p_{1, t-j}+\varepsilon_{1, t}\right.$

$\Delta p_{2, t=} \alpha_{2}\left(p_{1, t-1}-p_{2, t-1)}+\sum_{k=1}^{200} \varphi_{k} p_{1, t-k}+\sum_{m=1}^{200} \phi_{m} p_{1, t-m}+\varepsilon_{1, t}\right.$

where $\Delta p_{1, t}$ represents the change in the log price of the asset traded in market $i$ for time period $t$. The component shares are obtained from the normalized orthogonal vector of error correction coefficients

$C S_{1}=\gamma_{1}=\frac{\alpha_{2}}{\alpha_{2}-\alpha_{1}}, C S_{2}=\gamma_{2}=\frac{\alpha_{2}}{\alpha_{1}-\alpha_{2}}$

Given the covariance matrix of the reduced form of VECM error terms

$$
\Omega=\left(\begin{array}{cc}
\sigma_{1}^{2} & \rho \sigma_{1} \sigma_{2} \\
\rho \sigma_{1} \sigma_{2} & \sigma_{2}^{2}
\end{array}\right)
$$

and its Cholesky factorisation, $\Omega=M M^{\prime}$, where

$$
M=\left(\begin{array}{cc}
m_{11} & 0 \\
m_{12} & m_{22}
\end{array}\right)=\left(\begin{array}{cc}
\sigma_{1} & 0 \\
\rho \sigma_{2} & \sigma_{2}\left(1-\rho^{2}\right)^{\frac{1}{2}}
\end{array}\right)
$$


IS can be obtained as:

$$
I S_{1}=\frac{\left(\gamma_{1} m_{11}+\gamma_{2} m_{12}\right)^{2}}{\left(\gamma_{1} m_{11}+\gamma_{2} m_{12}\right)^{2}+\left(\gamma_{2} m_{22}+\gamma_{2} m_{12}\right)^{2}}, I S_{2}=\frac{\left(\gamma_{2} m_{22}\right)^{2}}{\left(\gamma_{1} m_{11}+\gamma_{2} m_{12}\right)^{2}+\left(\gamma_{2} m_{22}\right)^{2}}
$$

Because the estimates of IS are affected by the ordering of the price series in the VECM, Putniņš (2013) uses the approach advocated by Baillie et al. (2002) and calculates ILS under each of the two possible orderings and then takes the simple average.

$I L S_{1}=\left|\frac{I S_{1} C S_{2}}{I S_{2} C S_{1}}\right|, I L_{2}=\left|\frac{I S_{2} C S_{1}}{I S_{1} C S_{2}}\right|$

We calculate ILS for the Algo and Non-Algo transaction pre and post earnings announcement. The results are reported in Table A1. 


\section{Table A1: Information Leadership Share (ILS) Pre and Post Earnings Announcement}

This table presents the Information Leadership Share (ILS) developed in Yan and Zivot (2010) and Putniņš (2013).

$$
I L_{1}=\left|\frac{I S_{1} C S_{2}}{I S_{2} C S_{1}}\right|, I L_{2}=\left|\frac{I S_{2} C S_{1}}{I S_{1} C S_{2}}\right|
$$

where IS, is the Information Share metric developed by Hasbrouck (1995) and CS is the Component Share metric developed by Gonzalo and Granger (1995)

\begin{tabular}{llcc}
\hline Variable & Mean & Median & Std Dev \\
\hline Panel A. 30 minutes Pre Earnings Announcement & & & \\
Information Leadership Share AT & $48.73 \%$ & $54.06 \%$ & $41.48 \%$ \\
Information Leadership Share Non-AT & $51.27 \%$ & $45.94 \%$ & $41.48 \%$ \\
& & & \\
\hline Panel B. 30 minutes Post Earnings Announcement & & & \\
& & & \\
Information Leadership Share AT & $53.24 \%$ & $66.68 \%$ & $42.66 \%$ \\
Information Leadership Share Non-AT & & & \\
\end{tabular}

As the table shows, the average ILS for AT is smaller than that of non-AT before earnings announcements, and this relation reversed after earnings are announced. The median values of ILS are higher for AT both pre and post earnings announcements, while the median ILS for AT increases significantly in the post earnings announcement period. Our results are generally consistent with the results on information share reported in Table 6 . 


\section{Table 1: Descriptive statistics}

This table presents descriptive statistics for number of trades, trade size and volume on announcement days. Panel A and B report daily statistics and Panel C and D report statistics one hour before and one hour after announcements for algo and non algo trades. The number of trades is the number of trades for each stock averaged across all stocks. Trade size is the average volume per trade for each stock per day, averaged across all stocks. Volume is the total volume traded in each stock per day, averaged across all stocks.

\begin{tabular}{|c|c|c|c|c|c|c|}
\hline \multicolumn{4}{|c|}{ Buy Trades } & \multicolumn{3}{|c|}{ Sell Trades } \\
\hline & $\begin{array}{l}\text { No. of } \\
\text { Trades }\end{array}$ & Trade Size & Volume & $\begin{array}{l}\text { No. of } \\
\text { Trades }\end{array}$ & Trade Size & Volume \\
\hline \multicolumn{7}{|c|}{ Panel A: Daily Statistics for Algorithm-Initiated Trades } \\
\hline Mean & 974.50 & $7,378.58$ & $8,588,194.11$ & 843.00 & $9,588.86$ & $6,062,566.18$ \\
\hline Median & 673.00 & $2,306.42$ & $1,897,604.00$ & 542.00 & $2,562.37$ & $1,698,106.00$ \\
\hline Std Dev & $1,136.95$ & $13,682.36$ & $38,522,169.05$ & 884.27 & $22,576.50$ & $22,071,409.08$ \\
\hline Minimum & 70.00 & 166.10 & $42,480.00$ & 64.00 & 105.51 & $15,404.00$ \\
\hline Maximum & $7,905.00$ & $78,092.72$ & $354,926,100.00$ & $5,373.00$ & $145,821.95$ & $203,944,580.00$ \\
\hline \multicolumn{7}{|c|}{ Panel B: Daily Statistics for Non-Algorithm-Initiated Trades } \\
\hline Mean & 235.89 & $25,750.65$ & $4,830,952.04$ & 196.13 & $26,225.02$ & $3,716,715.03$ \\
\hline Median & 118.00 & $6,844.25$ & $1,038,520.00$ & 110.00 & $8,666.21$ & $1,198,490.00$ \\
\hline Std Dev & 322.70 & $64,841.42$ & $16,893,844.37$ & 234.68 & $63,363.52$ & $11,313,249.48$ \\
\hline Minimum & 20.00 & 317.14 & $22,642.00$ & 20.00 & 282.33 & $10,164.00$ \\
\hline Maximum & $2,217.00$ & $558,206.00$ & $135,738,210.00$ & $1,263.00$ & $538,223.82$ & $87,551,424.00$ \\
\hline \multicolumn{7}{|c|}{ Panel C: One Hour Pre- and Post-Earnings Announcement for Algorithm-Initiated Trades } \\
\hline Mean & 452.36 & $7,446.22$ & $4,141,531.67$ & 388.75 & $7,900.77$ & $2,538,422.82$ \\
\hline Median & 321.00 & $2,182.56$ & $752,122.00$ & 257.00 & 2, 482.69 & $736,588.00$ \\
\hline Std Dev & 529.28 & $14,373.04$ & $17,701,812.73$ & 401.96 & $21,490.12$ & $8,903,150.82$ \\
\hline Minimum & 30.00 & 131.96 & $74,424.00$ & 20.00 & 226.48 & $43,726.00$ \\
\hline Maximum & $3,213.00$ & $74,914.19$ & $123,762,950.00$ & $2,310.00$ & 148, & $62,401,010.00$ \\
\hline \multicolumn{7}{|c|}{ Panel D: One Hour Pre- and Post-Earnings Announcement for Non-Algorithm-Initiated Trades } \\
\hline Mean & 121.83 & $18,656.73$ & $1,788,999.71$ & 95.91 & $22,945.16$ & $1,710,765.14$ \\
\hline Median & 82.00 & $5,528.32$ & $516,052.00$ & 58.00 & $7,578.63$ & $486,990.00$ \\
\hline Std Dev & 137.90 & $27,730.21$ & $4,080,183.83$ & 101.89 & $42,732.75$ & $4,609,693.28$ \\
\hline Minimum & 20.00 & 611.70 & $57,580.00$ & 20.00 & 486.92 & $25,320.00$ \\
\hline Maximum & 837.00 & $125,427.33$ & $23,699,224.00$ & 570.00 & $218,307.24$ & $31,878,456.00$ \\
\hline
\end{tabular}




\section{Table 2: Descriptive statistics (1 Hour pre- and post- earnings announcement)}

This table presents the descriptive statistics for the number of trades, trade size and volume around announcement days. Mean, median and standard deviation for the following five minute intervals; $(-5,0),(-10,-5),(-15,-10),(-20,-40),(-40,-60)$ for pre- earnings announcement and $(0,5),(5,10),(10,15),(15,20)$, $(20,40),(40,60)$ for post- earnings announcement are reported for AT, non-AT initiated trades and the difference in these. The number of trades is the average number of trades, averaged per day across all stocks. Trade size is the average trade volume, averaged per day across all stocks. Volume is the total trade volume, averaged per day across all stocks. The differences of mean and median between AT and non-AT are tested using Kruskal-Wallis test and Wilcoxon test, respectively. $* * * ; *, *$ indicate significance at the $1 \%, 5 \%$ level and $10 \%$ level.

\begin{tabular}{|c|c|c|c|c|c|c|c|c|}
\hline & \multicolumn{3}{|c|}{ AT } & \multicolumn{3}{|c|}{ Non-AT } & \multicolumn{2}{|c|}{ AT - Non-AT } \\
\hline Period (min) & Mean & Median & STD & Mean & Median & STD & Mean & Median \\
\hline \multicolumn{9}{|c|}{ Panel A : One hour Pre Earnings Announcement for AT and Non-AT Initiated Buy Trades } \\
\hline \multicolumn{9}{|c|}{ No. of Trades } \\
\hline$(-5,0)$ & 62.19 & 62.63 & 57.74 & 33.35 & 25.65 & 31.70 & $28.84 * *$ & $36.98^{*}$ \\
\hline$(-10,-5)$ & 75.98 & 67.96 & 131.18 & 28.75 & 18.15 & 35.00 & $47.23 *$ & $49.81 * *$ \\
\hline$(-15,-10)$ & 60.71 & 49.05 & 78.42 & 29.25 & 33.75 & 58.50 & $31.46^{*}$ & $15.30 * *$ \\
\hline$(-20,-15)$ & 82.53 & 125.89 & 79.52 & 27.55 & 34.70 & 64.10 & $54.98 *$ & $91.19 * *$ \\
\hline$(-20,-40)$ & 104.35 & 107.55 & 99.75 & 28.55 & 34.30 & 64.05 & $75.80 *$ & $73.25 * *$ \\
\hline$(-40,-60)$ & 80.75 & 70.90 & 109.50 & 28.05 & 25.95 & 38.50 & $52.70 *$ & $44.95^{*}$ \\
\hline \multicolumn{9}{|c|}{ Trade Size } \\
\hline$(-5,0)$ & $4,026.93$ & $3,931.27$ & $1,493.49$ & $15,888.62$ & $16,317.69$ & $7,945.23$ & $-11,861.69 * *$ & $-12,386.42 * *$ \\
\hline$(-10,-5)$ & $4,642.46$ & $4,261.17$ & $1,434.11$ & $15,836.69$ & $13,746.47$ & $10,600.51$ & $-11,194.23 * *$ & $-9,485.30^{*}$ \\
\hline$(-15,-10)$ & $5,666.82$ & $4,449.92$ & $2,319.10$ & $15,489.26$ & $14,118.39$ & $10,889.44$ & $-9,822.44 * *$ & $-9,668.47 *$ \\
\hline$(-20,-15)$ & $5,797.67$ & $3,351.05$ & $3,786.30$ & $15,013.09$ & $13,639.57$ & $3,255.96$ & $-9,215.42 *$ & $-10,288.52 * *$ \\
\hline$(-20,-40)$ & $4,705.61$ & $3,839.89$ & $1,985.59$ & $15,977.18$ & $11,175.12$ & $19,247.88$ & $-11,271.57 * *$ & $-7,335.23 * *$ \\
\hline$(-40,-60)$ & $6,311.48$ & $5,998.90$ & $2,993.54$ & $17,405.43$ & $11,537.99$ & $27,157.96$ & $-11,093.95^{* *}$ & $\begin{array}{l}-5,539.09 * \\
\text { (continues) }\end{array}$ \\
\hline
\end{tabular}




\begin{tabular}{|c|c|c|c|c|c|c|c|c|}
\hline \multicolumn{4}{|c|}{ AT } & \multicolumn{3}{|c|}{ Non-AT } & \multicolumn{2}{|c|}{ AT-Non-AT } \\
\hline Period (min) & Mean & Median & STD & Mean & Median & STD & Mean & Median \\
\hline \multicolumn{9}{|c|}{ Volume } \\
\hline$(-5,0)$ & $250,352.08$ & $246,214.34$ & $86,232.14$ & $529,885.48$ & $418,548.71$ & $251,863.79$ & $-279,533.40 * *$ & $-172,334.37 *$ \\
\hline$(-10,-5)$ & $352,724.06$ & $289,596.87$ & $188,128.99$ & $455,304.75$ & $249,498.42$ & $371,017.82$ & $-102,580.69$ & $40,098.45$ \\
\hline$(-15,-10)$ & $344,053.16$ & $218,287.50$ & $181,871.81$ & $453,060.83$ & $476,495.67$ & $637,032.14$ & $-109,007.67$ & $-258,208.17$ \\
\hline$(-20,-15)$ & $478,490.17$ & $421,878.29$ & $301,091.40$ & $413,610.56$ & $473,292.96$ & $208,707.09$ & $64,879.61 * *$ & $-51,414.67 *$ \\
\hline$(-20,-40)$ & $491,030.62$ & $409,139.77$ & $198,062.99$ & $456,148.42$ & $383,306.50$ & $1,232,826.75$ & $34,882.20$ & $25,833.27$ \\
\hline$(-40,-60)$ & $509,633.69$ & $425,322.32$ & $327,792.91$ & $488,222.41$ & $299,410.90$ & $1,045,581.55$ & $21,411.28$ & $125,911.42$ \\
\hline \multicolumn{9}{|c|}{ Panel B : One hour Post Earnings Announcement for AT and Non-AT Initiated Buy Trades } \\
\hline \multicolumn{9}{|c|}{ No. of Trades } \\
\hline$(0,5)$ & 178.55 & 153.10 & 62.65 & 24.94 & 25.35 & 54.50 & $153.61 * * *$ & $127.75^{* *}$ \\
\hline$(5,10)$ & 171.31 & 173.90 & 131.50 & 64.44 & 49.85 & 46.05 & $106.87^{* *}$ & $124.05^{* *}$ \\
\hline$(10,15)$ & 118.00 & 131.35 & 70.10 & 56.91 & 48.80 & 40.30 & $61.09^{*}$ & $82.55^{* *}$ \\
\hline$(15,20)$ & 105.82 & 89.30 & 114.01 & 46.85 & 43.80 & 30.40 & $58.97^{*}$ & $45.50 * *$ \\
\hline$(20,40)$ & 110.90 & 120.30 & 87.75 & 48.90 & 44.65 & 34.20 & $62.00 * *$ & $75.65^{*}$ \\
\hline$(40,60)$ & 79.31 & 76.53 & 76.70 & 42.90 & 33.75 & 61.00 & $36.41^{*}$ & $42.78^{*}$ \\
\hline \multicolumn{9}{|c|}{ Trade Size } \\
\hline$(0,5)$ & $5,011.04$ & $4,498.87$ & $2,405.37$ & $11,742.89$ & $10,568.30$ & $2,529.80$ & $-6,731.85 * *$ & $-6,069.43 * *$ \\
\hline$(5,10)$ & $4,427.47$ & $4,128.59$ & $1,433.27$ & $12,681.49$ & $8,380.04$ & $10,243.92$ & $-8,254.02 * *$ & $-4,251.45^{* *}$ \\
\hline$(10,15)$ & $5,892.44$ & $4,832.03$ & $2,110.47$ & $12,208.21$ & $12,007.87$ & $3,821.77$ & $-6,315.77 * *$ & $-7,175.84^{*}$ \\
\hline$(15,20)$ & $5,636.32$ & $5,280.30$ & $2,476.55$ & $20,827.19$ & $11,702.49$ & $15,442.56$ & $-15,190.87^{*}$ & $-6,422.19^{*}$ \\
\hline$(20,40)$ & $5,645.61$ & $4,487.10$ & $3,079.12$ & $16,286.91$ & $14,447.04$ & $10,286.64$ & $-10,641.30^{*}$ & $-9,959.94 *$ \\
\hline$(40,60)$ & $5,480.28$ & $4,277.53$ & $3,487.73$ & $17,574.30$ & $14,279.53$ & $10,841.92$ & $-12,094.02 * *$ & $\begin{array}{l}-10,002.00 * \\
\text { (continues) }\end{array}$ \\
\hline
\end{tabular}




\begin{tabular}{|c|c|c|c|c|c|c|c|c|}
\hline \multicolumn{4}{|c|}{ AT } & \multicolumn{3}{|c|}{ Non-AT } & \multicolumn{2}{|c|}{ AT - Non-AT } \\
\hline Period (min) & Mean & Median & STD & Mean & Median & STD & Mean & Median \\
\hline \multicolumn{9}{|c|}{ Volume } \\
\hline$(0,5)$ & $884,689.99$ & $679,778.51$ & $150,684.90$ & $292,841.16$ & $267,906.44$ & $137,873.86$ & $591,848.83 * * *$ & $411,872.07 * *$ \\
\hline$(5,10)$ & $758,476.38$ & $717,962.49$ & $188,474.69$ & $817,227.65$ & $417,745.24$ & $471,732.34$ & - 58,751.27 & $300,217.25$ \\
\hline$(10,15)$ & $695,332.92$ & $634,687.11$ & $147,944.09$ & $794,751.21$ & $685,984.05$ & $154,017.32$ & - 99,418.29 & $-51,296.94$ \\
\hline$(15,20)$ & $596,459.52$ & $471,530.65$ & $282,344.04$ & $975,753.66$ & $512,569.28$ & $469,453.92$ & $-379,294.14^{* *}$ & $41,038.63 * *$ \\
\hline$(20,40)$ & $626,098.29$ & $539,798.65$ & $270,192.94$ & $796,429.99$ & $645,060.31$ & $351,802.96$ & $-170,331.70$ & $-105,261.66$ \\
\hline$(40,60)$ & $435,715.56$ & $326,940.98$ & $267,509.09$ & $753,937.65$ & $481,934.04$ & $661,357.38$ & $-318,222.09$ & $-154,993.06$ \\
\hline
\end{tabular}

Panel C : One hour Pre Earnings Announcement for AT and Non-AT Initiated Sell Trades

\begin{tabular}{|c|c|c|c|c|c|c|c|c|}
\hline \multicolumn{9}{|c|}{ No. of Trades } \\
\hline$(-5,0)$ & 70.95 & 75.15 & 59.75 & 33.15 & 25.60 & 39.90 & $37.80 * *$ & $49.55 * *$ \\
\hline$(-10,-5)$ & 76.88 & 55.50 & 122.60 & 25.75 & 19.20 & 40.10 & $51.13 * *$ & $36.30 * *$ \\
\hline$(-15,-10)$ & 62.59 & 53.30 & 53.62 & 26.55 & 31.25 & 56.15 & $36.04 *$ & $22.05 * *$ \\
\hline$(-20,-15)$ & 78.28 & 53.30 & 150.10 & 26.10 & 27.95 & 150.10 & $52.18^{*}$ & $25.35 * *$ \\
\hline$(-20,-40)$ & 106.68 & 112.21 & 134.34 & 24.75 & 28.55 & 79.05 & $81.93 * *$ & $83.66^{*}$ \\
\hline$(-40,-60)$ & 77.27 & 61.65 & 189.08 & 25.60 & 31.05 & 46.25 & $51.67 *$ & $30.60 * *$ \\
\hline \multicolumn{9}{|c|}{ Trade Size } \\
\hline$(-5,0)$ & $4,051.12$ & $3,956.98$ & $1,394.29$ & $15,391.30$ & $16,987.81$ & $7,877.05$ & $-11,340.18 * *$ & $-13,030.83 * *$ \\
\hline$(-10,-5)$ & $4,224.50$ & $3,985.03$ & $1,457.37$ & $15,222.69$ & $10,173.55$ & $12,530.37$ & $-10,998.19 * *$ & $-6,188.52 * *$ \\
\hline$(-15,-10)$ & $5,225.68$ & $6,619.10$ & $2,427.20$ & $15,503.71$ & $16,623.37$ & $11,742.88$ & $-10,278.03^{*}$ & $-10,004.27 * *$ \\
\hline$(-20,-15)$ & $5,918.24$ & $5,320.80$ & $1,121.23$ & $15,645.68$ & $15,341.12$ & $3,777.32$ & $-9,727.44 *$ & $-10,020.32 * *$ \\
\hline$(-20,-40)$ & $5,268.17$ & $5,208.47$ & $1,739.77$ & $16,038.92$ & $13,039.54$ & $15,086.85$ & $-10,770.75^{*}$ & $-7,831.07 *$ \\
\hline$(-40,-60)$ & $5,940.71$ & $5,197.20$ & $2,860.75$ & $17,669.28$ & $10,583.23$ & $29,614.94$ & $-11,728.57^{*}$ & $\begin{array}{l}-5,386.03 \\
\text { (continues) }\end{array}$ \\
\hline
\end{tabular}




\begin{tabular}{|c|c|c|c|c|c|c|c|c|}
\hline \multicolumn{4}{|c|}{$\mathrm{AT}$} & \multicolumn{3}{|c|}{ Non-AT } & \multicolumn{2}{|c|}{ AT-Non-AT } \\
\hline Period (min) & Mean & Median & STD & Mean & Median & STD & Mean & Median \\
\hline \multicolumn{9}{|c|}{ Volume } \\
\hline$(-5,0)$ & $283,781.01$ & $297,367.38$ & $83,308.58$ & $510,221.73$ & $434,887.85$ & $314,294.14$ & $-226,440.72 * *$ & $-137,520.47 *$ \\
\hline$(-10,-5)$ & $324,799.89$ & $221,169.07$ & $178,674.09$ & $391,984.34$ & $195,332.19$ & $502,467.83$ & $-67,184.45^{* *}$ & $25,836.88 * *$ \\
\hline$(-15,-10)$ & $327,098.56$ & $352,798.20$ & $130,151.88$ & $411,623.38$ & $519,480.44$ & $659,354.62$ & $-84,524.82 *$ & $-166,682.24 * *$ \\
\hline$(-20,-15)$ & $463,301.36$ & $283,598.48$ & $168,295.95$ & $408,352.25$ & $428,784.37$ & $566,976.29$ & $54,949.11^{* *}$ & $-145,185.89 *$ \\
\hline$(-20,-40)$ & $562,025.75$ & $584,444.72$ & $233,719.55$ & $396,963.25$ & $372,278.74$ & $1,192,615.56$ & $165,062.50$ & $212,165.98$ \\
\hline$(-40,-60)$ & $459,044.51$ & $320,404.26$ & $540,904.37$ & $452,333.54$ & $328,609.38$ & $1,369,691.09$ & $6,710.97$ & $-8,205.12$ \\
\hline
\end{tabular}

Panel D : One hour Post Earnings Announcement for AT and Non-AT Initiated Sell Trades

\begin{tabular}{|c|c|c|c|c|c|c|c|c|}
\hline \multicolumn{9}{|c|}{ No. of Trades } \\
\hline$(0,5)$ & 172.07 & 155.30 & 30.15 & 23.08 & 21.16 & 30.15 & $148.99 * *$ & $134.14 * *$ \\
\hline$(5,10)$ & 168.29 & 145.96 & 176.80 & 58.21 & 46.28 & 90.23 & $110.08^{* *}$ & $99.68 * *$ \\
\hline$(15,20)$ & 96.76 & 116.37 & 116.48 & 43.27 & 42.16 & 29.49 & $53.49 * *$ & $74.21 *$ \\
\hline$(20,40)$ & 98.20 & 125.45 & 39.55 & 48.85 & 49.65 & 42.00 & 49.35 & 75.80 \\
\hline \multicolumn{9}{|c|}{ Trade Size } \\
\hline$(0,5)$ & $4,967.03$ & $5,020.67$ & $1,519.95$ & $11,776.71$ & $11,913.97$ & $1,719.95$ & $-6,809.68 * *$ & $-6,893.30 * *$ \\
\hline$(5,10)$ & $4,123.72$ & $3,950.18$ & $1,323.55$ & $14,136.62$ & $12,577.06$ & $5,257.89$ & $-10,012.90 * *$ & $-8,626.88^{* *}$ \\
\hline$(10,15)$ & $5,076.84$ & $4,588.31$ & 1034.30 & $12,140.75$ & $12,214.83$ & $2,545.95$ & $-7,063.91 * *$ & $-7,626.52 *$ \\
\hline$(40,60)$ & $5,494.54$ & $4,550.15$ & $2,664.75$ & $18,117.60$ & $16,144.35$ & $9,219.91$ & $-12,623.06^{*}$ & $\begin{array}{c}-11,594.20 * \\
\text { (continues) }\end{array}$ \\
\hline
\end{tabular}




\begin{tabular}{|c|c|c|c|c|c|c|c|c|}
\hline \multicolumn{4}{|c|}{$\mathrm{AT}$} & \multicolumn{3}{|c|}{ Non-AT } & \multicolumn{2}{|c|}{ AT-Non-AT } \\
\hline Period (min) & Mean & Median & STD & Mean & Median & STD & Mean & Median \\
\hline \multicolumn{9}{|c|}{ Volume } \\
\hline$(0,5)$ & $854,689.99$ & $779,725.54$ & $45,826.49$ & $271,769.36$ & $252,097.42$ & $51,856.49$ & $582,920.63 * *$ & $527,628.12^{* *}$ \\
\hline$(5,10)$ & $693,996.42$ & $576,529.15$ & $234,002.99$ & $822,929.59$ & $582,017.90$ & $474,441.51$ & $-128,933.17^{*}$ & $-5,488.75^{*}$ \\
\hline$(10,15)$ & $467,933.27$ & $581,188.79$ & $203,471.34$ & $609,465.88$ & $510,580.03$ & $115,331.63$ & $-141,532.61 *$ & $70,608.76^{*}$ \\
\hline$(15,20)$ & $522,701.50$ & $562,915.02$ & $240,856.17$ & $870,181.50$ & $746,754.27$ & $320,489.00$ & $-347,480.00 *$ & $-183,839.25^{*}$ \\
\hline$(20,40)$ & $531,456.70$ & $575,607.31$ & $107,931.93$ & $817,938.48$ & $663,798.08$ & $434,662.99$ & $-286,481.78^{*}$ & $-88,190.77 *$ \\
\hline$(40,60)$ & $417,035.50$ & $342,398.88$ & $151,358.05$ & $675,786.58$ & $490,788.24$ & $608,514.27$ & $-258,751.08 *$ & $-148389.36^{*}$ \\
\hline
\end{tabular}




\section{Table 3: Order flow for AT and non-AT}

This table reports the total order flow within each interval for algorithmic and non-algorithmic trades surrounding earnings announcements. The order flow is calculated as the number of buy trades minus the number of sell trades. Standard errors are given in parentheses. Only announcements classified as good and bad news are included in the sample. *** indicates significance at the $1 \%$ level; ** indicates significance at the 5\% level; and * indicates significance at the $10 \%$.

\begin{tabular}{|c|c|c|c|c|}
\hline & \multicolumn{2}{|c|}{ Good News } & \multicolumn{2}{|c|}{ Bad News } \\
\hline Interval (unit!) & AT & Non-AT & AT & Non-AT \\
\hline$(-300,-270)$ & $\begin{array}{c}25 \\
(1.92)\end{array}$ & $\begin{array}{c}6 \\
(1.19)\end{array}$ & $\begin{array}{c}10 \\
(2.43)\end{array}$ & $\begin{array}{c}6 \\
(0.54)\end{array}$ \\
\hline$(-270,-240)$ & $\begin{array}{c}-22 \\
(2.43)\end{array}$ & $\begin{array}{c}5 \\
(0.53)\end{array}$ & $\begin{array}{c}11 \\
(1.25)\end{array}$ & $\begin{array}{c}2 \\
(0.36)\end{array}$ \\
\hline$(-240,-180)$ & $\begin{array}{c}29 \\
(4.52)\end{array}$ & $\begin{array}{c}9 \\
(1.05)\end{array}$ & $\begin{array}{c}1 \\
(3.26)\end{array}$ & $\begin{array}{c}-1 \\
(1.03)\end{array}$ \\
\hline$(-180,-120)$ & $\begin{array}{c}1 \\
(3.72)\end{array}$ & $\begin{array}{c}-2 \\
(1.54)\end{array}$ & $\begin{array}{c}35^{* *} \\
(2.66)\end{array}$ & $\begin{array}{c}15 \\
(1.24)\end{array}$ \\
\hline$(-120,-90)$ & $\begin{array}{c}-22 \\
(3.05)\end{array}$ & $\begin{array}{c}8 \\
(1.42)\end{array}$ & $\begin{array}{c}-7 \\
(2.95)\end{array}$ & $\begin{array}{c}3 \\
(0.37)\end{array}$ \\
\hline$(-90,-60)$ & $\begin{array}{c}-11 \\
(2.11)\end{array}$ & $\begin{array}{c}3 \\
(1.09)\end{array}$ & $\begin{array}{c}11 \\
(1.52)\end{array}$ & $\begin{array}{c}-1 \\
(0.18)\end{array}$ \\
\hline$(-60,-30)$ & $\begin{array}{c}0 \\
(3.05)\end{array}$ & $\begin{array}{c}2 \\
(1.52)\end{array}$ & $\begin{array}{c}1 \\
(1.58)\end{array}$ & $\begin{array}{c}0 \\
(0.55)\end{array}$ \\
\hline$(-30,-20)$ & $\begin{array}{c}14 * \\
(1.7)\end{array}$ & $\begin{array}{c}3 \\
(1.01)\end{array}$ & $\begin{array}{c}-4 \\
(0.9)\end{array}$ & $\begin{array}{c}1 \\
(0.56)\end{array}$ \\
\hline$(-20,-10)$ & $\begin{array}{c}12 \\
(1.89)\end{array}$ & $\begin{array}{c}9 \\
(2.12)\end{array}$ & $\begin{array}{c}-8 \\
(1.17)\end{array}$ & $\begin{array}{c}1 \\
(0.23)\end{array}$ \\
\hline$(-10,0)$ & $\begin{array}{c}8 \\
(1.69)\end{array}$ & $\begin{array}{c}6^{*} \\
(0.49)\end{array}$ & $\begin{array}{c}-6 \\
(1.28)\end{array}$ & $\begin{array}{c}0 \\
(0)\end{array}$ \\
\hline$(0,10)$ & $\begin{array}{l}40^{* * * *} \\
(2.35)\end{array}$ & $\begin{array}{c}-6 \\
(1.42)\end{array}$ & $\begin{array}{l}-10^{*} \\
(2.75)\end{array}$ & $\begin{array}{c}10 \\
(0.74)\end{array}$ \\
\hline$(10,20)$ & $\begin{array}{c}18 \\
(2.13)\end{array}$ & $\begin{array}{c}4 \\
(0.98)\end{array}$ & $\begin{array}{c}-14^{* *} \\
(1.18)\end{array}$ & $\begin{array}{c}3 \\
(0.81)\end{array}$ \\
\hline$(20,30)$ & $\begin{array}{c}3 \\
(2.99)\end{array}$ & $\begin{array}{c}-3 \\
(0.65)\end{array}$ & $\begin{array}{c}-2 \\
(0.81)\end{array}$ & $\begin{array}{c}1 \\
(0.71)\end{array}$ \\
\hline$(30,60)$ & $\begin{array}{c}65^{* * *} \\
(3.6)\end{array}$ & $\begin{array}{c}14 \\
(2.4)\end{array}$ & $\begin{array}{c}10 \\
(1.57)\end{array}$ & $\begin{array}{c}8 \\
(0.86)\end{array}$ \\
\hline$(60,90)$ & $\begin{array}{c}56^{* *} \\
(5.38)\end{array}$ & $\begin{array}{c}-9 \\
(1.03)\end{array}$ & $\begin{array}{c}-26 \\
(2.98)\end{array}$ & $\begin{array}{c}2 \\
(1.3)\end{array}$ \\
\hline$(90,120)$ & $\begin{array}{c}15^{*} \\
(3.25)\end{array}$ & $\begin{array}{c}4 \\
(2.27)\end{array}$ & $\begin{array}{c}-6 \\
(3.92)\end{array}$ & $\begin{array}{c}-2 \\
(0.98)\end{array}$ \\
\hline$(120,180)$ & $\begin{array}{c}-43 \\
(7.04)\end{array}$ & $\begin{array}{c}18^{*} \\
(1.94)\end{array}$ & $\begin{array}{c}7 \\
(1.53)\end{array}$ & $\begin{array}{c}-2 \\
(1.7)\end{array}$ \\
\hline$(180,240)$ & $\begin{array}{c}-4 \\
(2.14)\end{array}$ & $\begin{array}{c}-12 \\
(1.45)\end{array}$ & $\begin{array}{c}39 \\
(2.7)\end{array}$ & $\begin{array}{c}10^{* *} \\
(1.31)\end{array}$ \\
\hline$(240,270)$ & $\begin{array}{c}-13 \\
(4.93)\end{array}$ & $\begin{array}{c}11 \\
(1.45)\end{array}$ & $\begin{array}{c}3 \\
(1.78)\end{array}$ & $\begin{array}{c}-9 \\
(0.85)\end{array}$ \\
\hline$(270,300)$ & $\begin{array}{c}5 \\
(3.36)\end{array}$ & $\begin{array}{c}2 \\
(1.2)\end{array}$ & $\begin{array}{c}-6 \\
(1.66)\end{array}$ & $\begin{array}{c}-7 \\
(0.77)\end{array}$ \\
\hline
\end{tabular}




\section{Table 4: Trading profits}

In this table, we follow Erenburg et al (2006) and report per trade profits averaged across all stocks and trades on announcement days at time $\mathrm{t}$ :

$$
\text { Profit }_{t}=D_{t}\left(R P_{t}-P_{t}\right) Q_{t},
$$

where $R P_{t}$ is the reference price, $P_{t}$ is the trade price, $D_{t}$ is an indicator variable equal to one for buys and minus one for sells, $Q_{t}$ is the trade volume. The reference price is calculated as the average trade price during the sixth minute after the announcement. Cum AT (Non-AT) profit is the cumulative profit and No. of AT (Non-AT) is the number of trades for AT and non-AT. Difference is the absolute value of Cum AT profit - Cum Non-AT profit. The symbols ***, **, and * indicate significance at the $1 \%, 5 \%$ and $10 \%$ level.

\begin{tabular}{cccccccr}
\hline $\begin{array}{c}\text { Interval } \\
(\mathrm{sec})\end{array}$ & $\begin{array}{c}\text { AT } \\
\text { Profit }\end{array}$ & $\begin{array}{c}\text { Non-AT } \\
\text { Profit }\end{array}$ & $\begin{array}{c}\text { No. of } \\
\text { AT } \\
\text { Trades }\end{array}$ & $\begin{array}{c}\text { No. of } \\
\text { Non-AT } \\
\text { Trades }\end{array}$ & $\begin{array}{c}\text { Cum } \\
\text { AT } \\
\text { Profit }\end{array}$ & $\begin{array}{c}\text { Cum } \\
\text { Non-AT } \\
\text { Profit }\end{array}$ & Difference \\
\hline$(-160,-150)$ & 376.74 & -616.6 & 4 & 4 & 376.74 & -616.60 & 993.34 \\
$(-150,-140)$ & 78.04 & -146.29 & 5 & 6 & 454.79 & -762.89 & 1217.68 \\
$(-140,-130)$ & 12.8 & -75.45 & 5 & 3 & 467.59 & -838.34 & 1305.93 \\
$(-130,-120)$ & 0.83 & -769.75 & 5 & 6 & 468.42 & -1608.09 & 2076.51 \\
$(-120,-110)$ & 49.87 & -153.92 & 5 & 4 & 518.29 & -1762.01 & 2280.30 \\
$(-110,-100)$ & -53.81 & -87.65 & 5 & 3 & 464.48 & -1849.66 & 2314.14 \\
$(-100,-90)$ & -13.31 & 339.33 & 4 & 2 & 451.17 & -1510.33 & 1961.50 \\
$(-90,-80)$ & -27.41 & 3.25 & 3 & 3 & 423.76 & -1507.08 & 1930.84 \\
$(-80,-70)$ & -96.5 & -1303.54 & 5 & 5 & 327.26 & -2810.62 & $3137.88^{*}$ \\
$(-70,-60)$ & -264.67 & 456.87 & 5 & 3 & 62.59 & -2353.75 & 2416.34 \\
$(-60,-50)$ & -268.51 & -46.67 & 5 & 3 & -205.92 & -2400.42 & 2194.50 \\
$(-50,-40)$ & -199.42 & -243.64 & 5 & 5 & -405.34 & -2644.06 & 2238.72 \\
$(-40,-30)$ & -199.77 & -62.31 & 5 & 3 & -605.11 & -2706.37 & 2101.26 \\
$(-30,-20)$ & 2.97 & 106.41 & 5 & 4 & -608.08 & -2599.96 & 1991.88 \\
$(-20,-10)$ & 132.52 & 216.14 & 5 & 3 & -475.56 & -2559.07 & 2083.51 \\
$(-10,0)$ & -221.58 & -175.25 & 5 & 2 & -697.14 & -2621.66 & 1924.52 \\
$(0,10)$ & 87.96 & -62.59 & 9 & 5 & -609.18 & -2832.26 & 2223.08 \\
$(10,20)$ & 173.58 & -210.6 & 7 & 4 & -435.59 & -2900.49 & $2464.9 *$ \\
$(20,30)$ & 347.88 & -68.23 & 5 & 3 & -87.71 & -3141.55 & 3053.84 \\
$(30,40)$ & 161.8 & -241.06 & 3 & 2 & 74.09 & -3291.40 & $3365.49 * *$ \\
$(40,50)$ & 365.9 & -149.85 & 4 & 3 & 439.98 & -3418.93 & $3858.91 *$ \\
$(50,60)$ & 232.52 & -127.53 & 4 & 3 & 672.50 & -4166.38 & 4838.88 \\
& & & & & & &
\end{tabular}




\begin{tabular}{cccccccr}
\hline $\begin{array}{c}\text { Interval } \\
(\mathrm{sec})\end{array}$ & $\begin{array}{c}\text { AT } \\
\text { Profit }\end{array}$ & $\begin{array}{c}\text { Non-AT } \\
\text { Profit }\end{array}$ & $\begin{array}{c}\text { No. of } \\
\text { AT }\end{array}$ & $\begin{array}{c}\text { No. of } \\
\text { Non-AT }\end{array}$ & $\begin{array}{c}\text { Cum } \\
\text { AT }\end{array}$ & $\begin{array}{c}\text { Cum } \\
\text { Non-AT }\end{array}$ & Difference \\
\hline$(60,70)$ & 788.61 & -747.45 & 4 & 5 & 1461.11 & -3982.94 & 5444.05 \\
$(70,80)$ & 530.25 & 183.44 & 8 & 5 & 1991.36 & -4382.53 & 6373.89 \\
$(80,90)$ & 2178.09 & -399.59 & 7 & 3 & 4169.45 & -4669.87 & $8839.32^{* * *}$ \\
$(90,100)$ & 840.27 & -287.34 & 5 & 4 & 5009.72 & -5220.30 & $10230.02^{* *}$ \\
$(100,110)$ & 601.95 & -550.43 & 5 & 3 & 5611.67 & -5691.17 & $11302.84^{* *}$ \\
$(110,120)$ & 226.75 & -470.87 & 7 & 4 & 5838.42 & -5941.33 & $11779.75^{*}$ \\
$(120,130)$ & 16.74 & -250.16 & 5 & 5 & 5855.17 & -7139.76 & 12994.93 \\
$(130,140)$ & 62.58 & -1198.43 & 4 & 4 & 5917.74 & -7359.14 & 13276.88 \\
$(140,150)$ & 9.02 & -219.38 & 5 & 3 & 5926.76 & -7370.47 & 13297.23 \\
$(150,160)$ & 356.47 & -11.33 & 5 & 3 & 6283.23 & -2559.07 & 8842.3 \\
\hline
\end{tabular}


Table 5: Empirical analysis of the temporal relation between AT, non-AT and market returns

This table presents the results of a VAR analysis of the associations between AT, non-AT and market returns surrounding corporate earnings announcements. The following system of three equations is estimated:

$$
\begin{aligned}
& \text { return }_{i, t}=\alpha_{0}+\chi_{1} D_{\text {pre }}+\varphi_{1} D_{\text {post }}+\sum_{j=1}^{5} \gamma_{1, j} \text { return }_{t-j} * D_{\text {pre }}+\sum_{j=1}^{5} \delta_{1, j} \text { algo }_{t-j} * D_{\text {pre }}+\sum_{j=1}^{5} \omega_{1, j} \text { nonAlgo }_{t-j}{ }^{*} D_{\text {pre }}+ \\
& \sum_{j=1}^{5} \varsigma_{1, j} \text { return }_{t-j} * D_{\text {post }}+\sum_{j=1}^{5} \sigma_{1, j} \text { algo }_{t-j} * D_{\text {post }}+\sum_{j=1}^{5} \gamma_{1, j} \text { nonAlgo }_{t-j} * D_{\text {post }}+\sum_{j=1}^{5} \pi_{1, j} \text { return }_{i, t-j}+\sum_{j=1}^{5} \beta_{1, j} a l g o_{i, t-j}+
\end{aligned}
$$

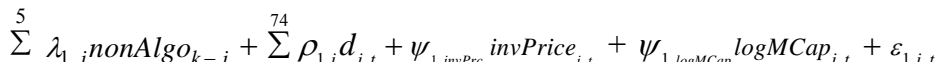

$$
\begin{aligned}
& \operatorname{algo}_{i, t}=\alpha_{1}+\chi_{2} D_{\text {pre }}+\varphi_{2} D_{\text {post }}+\sum_{j=1}^{5} \gamma_{2, j} \text { return }_{t-j} * D_{\text {pre }}+\sum_{j=1}^{5} \delta_{2, j} \text { algo }_{t-j} * D_{\text {pre }}+\sum_{j=1}^{5} \omega_{2, j} \text { nonAlgo } t-j * D_{\text {pre }}+ \\
& \sum_{j=1}^{5} \varsigma_{2, j} \text { return }_{t-j} * D_{\text {post }}+\sum_{j=1}^{5} \sigma_{2, j} \text { algo }_{t-j}{ }^{*} D_{\text {post }}+\sum_{j=1}^{5} \gamma_{2, j} \text { nonAlgo } t-j^{*} D_{\text {post }}+\sum_{j=1}^{5} \pi_{2, j} \text { Return }_{i, t-j}+\sum_{j=1}^{5} \beta_{2, j} a \operatorname{algo}_{i, t-j}+
\end{aligned}
$$

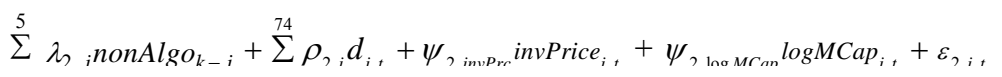

$$
\begin{aligned}
& \text { nonAlgo }_{i, t}=\alpha_{2}+\chi_{3} D_{\text {pre }}+\varphi_{3} D_{\text {post }}+\sum_{j=1}^{5} \gamma_{3, j} \text { return }_{t-j} * D_{\text {pre }}+\sum_{j=1}^{5} \delta_{3, j} \text { algo }_{t-j}{ }^{*} D_{\text {pre }}+\sum_{j=1}^{5} \omega_{3, j} \text { nonAlgo }_{t-j}{ }^{*} D_{\text {pre }}+ \\
& \sum_{j=1}^{5} \varsigma_{3, j} \text { return }_{t-j} * D_{\text {post }}+\sum_{j=1}^{5} \sigma_{3, j} \text { algo }_{t-j} * D_{\text {post }}+\sum_{j=1}^{5} \gamma_{3, j} \text { nonAlgo }_{t-j} * D_{\text {post }}+\sum_{j=1}^{5} \pi_{3, j} \text { Return }_{i, t-j}+\sum_{j=1}^{5} \beta_{3, j} \text { algo }_{i, t-j}+
\end{aligned}
$$

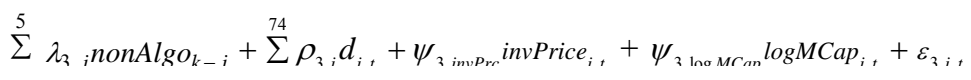

where algo $_{i, t}$ is the 30 second imbalance for AT initiated trades and nonAlgo $o_{i, t}$ is the 30 second imbalance for non-AT initiated trades for company $i$ at time $t$. Imbalance is calculated as buy volume - sell volume. return $_{i, t}$ is 30 second return. $D_{\text {pre }}$ is a dummy variable that equal 1 for the first 300 seconds before the announcement and $D_{\text {post }}$ is a dummy variable that equals 1 for the first 300 seconds after the announcement. The following control variables are included, $d_{i, t}$ is dummy variable for each company, invPrice $_{i, t}$ is inverse price and $\operatorname{logMCap}{ }_{i, t}$ is log of market capitalization. F statistics are based on the null hypothesis that all company dummy variables are jointly insignificant. Newey-West (1987) standard errors are reported in parenthesis. ${ }^{* *}, * *$ and $*$ indicates statistical significance of the coefficients at the $1 \%, 5 \%$ and $10 \%$ level, respectively. 


$$
\text { return }_{i, t} \text { a } \quad \text { algo }_{i, t} \quad \text { nonAlgo }_{i, t}
$$

Panel A : ( Intercepts ) Pre and post earnings announcement

\begin{tabular}{lccc}
\hline$\alpha$ & 5720.64 & -856.91 & 6460.50 \\
& $(3770.23)$ & $(472.01)$ & $(9535.10)$ \\
$D_{\text {pre }}$ & 2377.97 & -23375.40 & -1406.92 \\
& $(1281.53)$ & $(12237.02)$ & $(1340.80)$ \\
$D_{\text {post }}$ & $3519.04 * *$ & $7412.49 * *$ & 2638.333 \\
& $(1140.86)$ & $(2265.40)$ & $(2156.71)$ \\
\hline
\end{tabular}

Panel B: Lagged variables five minute pre earnings announcement

\begin{tabular}{|c|c|c|c|}
\hline return $_{t-1} * D_{\text {pre }}$ & $\begin{array}{c}156.72 * * \\
(56.10)\end{array}$ & $\begin{array}{c}282.96 * * \\
(102.50)\end{array}$ & $\begin{array}{c}164.33 * * \\
(59.02)\end{array}$ \\
\hline return $_{t-2} * D_{\text {pre }}$ & $\begin{array}{c}98.08 \\
(69.88)\end{array}$ & $\begin{array}{l}185.54 \\
(107.7)\end{array}$ & $\begin{array}{l}144.46^{*} \\
(70.42)\end{array}$ \\
\hline return $_{t-3} * D_{\text {pre }}$ & $\begin{array}{c}35.98 \\
(77.05)\end{array}$ & $\begin{array}{c}170.86 \\
(285.64)\end{array}$ & $\begin{array}{c}81.82 \\
(928.90)\end{array}$ \\
\hline return $_{t-4} * D_{\text {pre }}$ & $\begin{array}{c}6.31 \\
(5.39)\end{array}$ & $\begin{array}{l}-50.39 \\
(36.91)\end{array}$ & $\begin{array}{c}38.99 \\
(709.51)\end{array}$ \\
\hline return $_{t-5} * D_{\text {pre }}$ & $\begin{array}{l}-2.13 \\
(51.1)\end{array}$ & $\begin{array}{l}-82.69 \\
(46.27)\end{array}$ & $\begin{array}{l}-135.07 \\
(719.90)\end{array}$ \\
\hline algo $_{t-1} * D_{\text {pre }}$ & $\begin{array}{c}0.0917^{* *} \\
(0.0323)\end{array}$ & $\begin{array}{c}0.1603 * * * \\
(0.0335)\end{array}$ & $\begin{array}{l}0.1479 \\
(0.147)\end{array}$ \\
\hline $\operatorname{algo}_{t-2} * D_{p r e}$ & $\begin{array}{c}0.0526 \\
(0.0577)\end{array}$ & $\begin{array}{c}0.1512 \\
(0.1417)\end{array}$ & $\begin{array}{c}0.1233 \\
(0.0898)\end{array}$ \\
\hline $\operatorname{algo}_{t-3} * D_{p r e}$ & $\begin{array}{c}0.0405 \\
(0.0571)\end{array}$ & $\begin{array}{c}0.0895 \\
(0.1927)\end{array}$ & $\begin{array}{l}0.07403 \\
(0.0651)\end{array}$ \\
\hline $\operatorname{algo}_{t-4} * D_{p r e}$ & $\begin{array}{l}-0.0003 \\
(0.0007)\end{array}$ & $\begin{array}{c}0.0064 \\
(0.0133)\end{array}$ & $\begin{array}{l}0.0329 \\
(0.032)\end{array}$ \\
\hline $\operatorname{algo}_{t-5} * D_{p r e}$ & $\begin{array}{l}-0.0023 \\
(0.0061)\end{array}$ & $\begin{array}{c}0.0032 \\
(0.0036)\end{array}$ & $\begin{array}{l}-0.0119 \\
(0.0239)\end{array}$ \\
\hline $\operatorname{nonAlgo}_{t-1} * D_{\text {pre }}$ & $\begin{array}{c}0.0442 * * * \\
(0.0073)\end{array}$ & $\begin{array}{c}0.0739 * * * \\
(0.0062)\end{array}$ & $\begin{array}{c}0.0914 * * * \\
(0.0105)\end{array}$ \\
\hline nonAlgo ${ }_{t-2} * D_{\text {pre }}$ & $\begin{array}{c}0.0219 * * \\
(0.0071)\end{array}$ & $\begin{array}{c}0.0356 * * * \\
(0.0065)\end{array}$ & $\begin{array}{l}0.0622^{*} \\
(0.0314)\end{array}$ \\
\hline $\operatorname{nonAlgo}_{t-3} * D_{\text {pre }}$ & $\begin{array}{c}0.0144 * * \\
(0.0056)\end{array}$ & $\begin{array}{c}0.0269 * * * \\
(0.0061)\end{array}$ & $\begin{array}{c}0.0181 \\
(0.0167)\end{array}$ \\
\hline $\operatorname{nonAlgo}_{t-4} * D_{\text {pre }}$ & $\begin{array}{c}0.0103 \\
(0.0093)\end{array}$ & $\begin{array}{c}0.0168 \\
(0.0233)\end{array}$ & $\begin{array}{c}0.0076 \\
(0.0116)\end{array}$ \\
\hline nonAlgo $_{t-5} * D_{\text {pre }}$ & $\begin{array}{c}0.0008 \\
(0.0023)\end{array}$ & $\begin{array}{c}0.0067 \\
(0.0064)\end{array}$ & $\begin{array}{l}-0.0442 \\
(0.0507) \\
\text { (continues) }\end{array}$ \\
\hline
\end{tabular}


Panel C: Lagged variables five minute post earnings

\begin{tabular}{|c|c|c|c|}
\hline return $_{t-1} * D_{\text {post }}$ & $\begin{array}{c}437.00^{* * * *} \\
(118)\end{array}$ & $\begin{array}{l}672.67 * * \\
(217.09)\end{array}$ & $\begin{array}{c}117.87 \\
(373.02)\end{array}$ \\
\hline return $_{t-2} * D_{\text {post }}$ & $\begin{array}{c}356.00^{* *} \\
(122)\end{array}$ & $\begin{array}{l}562.32 * \\
(256.1)\end{array}$ & $\begin{array}{c}51.19 \\
(246.50)\end{array}$ \\
\hline return $_{t-3} * D_{\text {post }}$ & $\begin{array}{c}236.481^{*} \\
(107.5)\end{array}$ & $\begin{array}{l}353.09 \\
(216.5)\end{array}$ & $\begin{array}{c}47.07 \\
(345.18)\end{array}$ \\
\hline return $_{t-4} * D_{\text {post }}$ & $\begin{array}{l}184.31 \\
(236)\end{array}$ & $\begin{array}{l}105.87 \\
(85.78)\end{array}$ & $\begin{array}{c}12.72 \\
(887.03)\end{array}$ \\
\hline return ${ }_{t-5} * D_{\text {post }}$ & $\begin{array}{l}-265 \\
(462)\end{array}$ & $\begin{array}{l}77.30 \\
(62.83)\end{array}$ & $\begin{array}{c}-95.73 \\
(849.70)\end{array}$ \\
\hline $\operatorname{algo}_{t-1} * D_{\text {post }}$ & $\begin{array}{c}0.1447 * * * \\
(0.0003)\end{array}$ & $\begin{array}{c}0.5176^{* * * *} \\
(0.0049)\end{array}$ & $\begin{array}{c}0.9185 * * * \\
(0.272)\end{array}$ \\
\hline $\operatorname{algo}_{t-2} * D_{\text {post }}$ & $\begin{array}{c}0.0887 * * * \\
(0.0241)\end{array}$ & $\begin{array}{c}0.2597 * * \\
(0.0091)\end{array}$ & $\begin{array}{c}0.5250 * * * \\
(0.0585)\end{array}$ \\
\hline $\operatorname{algo}_{t-3} * D_{\text {post }}$ & $\begin{array}{c}0.0739 * * * \\
(0.0062)\end{array}$ & $\begin{array}{c}0.0853 * * \\
(0.0279)\end{array}$ & $\begin{array}{l}0.2306^{*} \\
(0.1125)\end{array}$ \\
\hline $\operatorname{algo}_{t-4} * D_{\text {post }}$ & $\begin{array}{c}0.0392 \\
(0.0409)\end{array}$ & $\begin{array}{c}0.0703 \\
(0.0741)\end{array}$ & $\begin{array}{c}0.0827 \\
(0.0524)\end{array}$ \\
\hline $\operatorname{algo}_{t-5} * D_{\text {post }}$ & $\begin{array}{c}0.0041 \\
(0.0127)\end{array}$ & $\begin{array}{l}-0.0012 \\
(0.0031)\end{array}$ & $\begin{array}{c}0.0940 \\
(0.0585)\end{array}$ \\
\hline nonAlgo $_{t-1} * D_{\text {post }}$ & $\begin{array}{l}0.0125 * * \\
(0.0047)\end{array}$ & $\begin{array}{c}0.1259 \\
(0.1079)\end{array}$ & $\begin{array}{c}0.0943 \\
(0.1024)\end{array}$ \\
\hline $\operatorname{nonAlgo}_{t-2} * D_{\text {post }}$ & $\begin{array}{c}0.0072 \\
(0.0044)\end{array}$ & $\begin{array}{c}0.0984 \\
(0.1098)\end{array}$ & $\begin{array}{c}0.0401 \\
(0.0606)\end{array}$ \\
\hline $\operatorname{nonAlgo}_{t-3} * D_{\text {post }}$ & $\begin{array}{c}0.0016 \\
(0.0034)\end{array}$ & $\begin{array}{c}0.0717 \\
(0.1108)\end{array}$ & $\begin{array}{c}0.0366 \\
(0.0668)\end{array}$ \\
\hline $\operatorname{nonAlgo}_{t-4} * D_{\text {post }}$ & $\begin{array}{c}0.0002 \\
(0.0033)\end{array}$ & $\begin{array}{c}0.0361 \\
(0.1102)\end{array}$ & $\begin{array}{c}0.0133 \\
(0.0108)\end{array}$ \\
\hline $\operatorname{nonAlgo}_{t-5} * D_{\text {post }}$ & $\begin{array}{l}-0.0058 \\
(0.0045)\end{array}$ & $\begin{array}{c}0.0138 \\
(0.1016)\end{array}$ & $\begin{array}{l}-0.0908 \\
(0.0675)\end{array}$ \\
\hline
\end{tabular}

Panel D: Auto-regressive lagged variables during bench mark

\begin{tabular}{lccc}
\multicolumn{4}{c}{ period $^{\mathrm{b}}$} \\
\hline Return $_{i, t-1}$ & $66275.80^{* * *}$ & $170.52^{*}$ & $146.66^{*}$ \\
Return $_{i, t-2}$ & $(10570)$ & $(84.49)$ & $(74.61)$ \\
Return $_{i, t-3}$ & $42153.4 * * *$ & 117.39 & 138.36 \\
Return $_{i, t-4}$ & $(11450)$ & $(86.2)$ & $(78.21)$ \\
Return $_{i, t-5}$ & $(11110)$ & $(84.2)$ & $(109.1)$ \\
algo $_{i, t-1}$ & 16549.01 & 81.27 & 41.65 \\
algo $_{i, t-2}$ & $(13350)$ & $(87.02)$ & $(57.76)$ \\
algo $_{i, t-3}$ & 5530.10 & 46.979 & -15.38 \\
algo $_{i, t-4}$ & $(9060)$ & $(116.17)$ & $(55.49)$ \\
algo $_{i, t-5}$ & $0.0268 * * *$ & $0.525 * * *$ & 0.0536 \\
& $(0.0061)$ & $(0.0585)$ & $(0.0314)$ \\
& $0.0104 * *$ & $0.3456 * * *$ & 0.0120 \\
& $(0.0035)$ & $(0.0352)$ & $(0.0261)$ \\
& 0.0067 & $0.1603 * * *$ & 0.0111 \\
& $(0.0064)$ & $(0.0335)$ & $(0.0292)$ \\
& 0.0026 & 0.0354 & -0.0431 \\
& $(0.0035)$ & $(0.0273)$ & $(0.0336)$ \\
& -0.0032 & 0.0204 & -0.0256 \\
& $(0.0031)$ & $(0.0243)$ & $(0.0167)$ \\
& & & $($ continues) \\
\hline
\end{tabular}




\begin{tabular}{|c|c|c|c|}
\hline nonAlgo $_{i, t-1}$ & $\begin{array}{c}0.0066^{* * *} \\
(0.0010)\end{array}$ & $\begin{array}{c}0.0062 \\
(0.0189)\end{array}$ & $\begin{array}{c}0.5150 * * * \\
(0.0505)\end{array}$ \\
\hline nonAlgo $_{i, t-2}$ & $\begin{array}{c}0.0023 \\
(0.0017)\end{array}$ & $\begin{array}{c}0.0057 \\
(0.0128)\end{array}$ & $\begin{array}{c}0.1663 * * * \\
(0.0437)\end{array}$ \\
\hline nonAlgo $_{i, t-3}$ & $\begin{array}{c}0.0012 \\
(0.0008)\end{array}$ & $\begin{array}{c}0.0042 \\
(0.0108)\end{array}$ & $\begin{array}{l}0.0636^{*} \\
(0.0288)\end{array}$ \\
\hline nonAlgo $_{i, t-4}$ & $\begin{array}{c}-0.0008 \\
(0.0018)\end{array}$ & $\begin{array}{l}-0.0191 \\
(0.0126)\end{array}$ & $\begin{array}{l}0.0086 \\
(0.050)\end{array}$ \\
\hline nonAlgo $_{i, t-5}$ & $\begin{array}{c}-0.0015 \\
(0.0018)\end{array}$ & $\begin{array}{l}-0.0991 \\
(0.0515)\end{array}$ & $\begin{array}{c}0.0222 \\
(0.0399)\end{array}$ \\
\hline \multicolumn{4}{|c|}{ Panel E: Control variables } \\
\hline invPrice $_{i, t}$ & $\begin{array}{l}-3168.21 \\
(3770.23)\end{array}$ & $\begin{array}{l}-3677.97 \\
(3373.62)\end{array}$ & $\begin{array}{c}-3334.38 * * \\
(1137.93)\end{array}$ \\
\hline $\log M C a p_{i, t}$ & $\begin{array}{c}-968.02 \\
(4210.01)\end{array}$ & $\begin{array}{l}148.84 * \\
(68.71)\end{array}$ & $\begin{array}{c}-770.33 \\
(1249.21)\end{array}$ \\
\hline$F$-Test $\left(d_{i, t}\right)$ & $4.59 * * *$ & $6.34 * * *$ & $4.85 * * *$ \\
\hline
\end{tabular}

Note (1) a denotes coefficients for return $n_{i, t}$ equations have been enlarged by $10^{5}$ and (b) Bench mark period is defined as twenty five minute before and after the five minute pre and post Earning Announcements.

\section{Table 6: Information share statistics of AT and Non-AT}

This table presents the information share ratio (Hasbrouck, 1995), 30 minutes before and 30 minutes after earnings announcement. The following vector error correction model (VECM) is used:

$$
\Delta p_{t}=\gamma \alpha^{\prime} p_{t-1}+\sum_{i=1}^{k} A_{i} \Delta p_{t-i}+\varepsilon_{t}
$$

where $p_{t}$ is an vector of cointegrated prices, $A_{i}$ are $n \times n$ matrices of autoregressive coefficients, $k$ is the number of lags, $\alpha^{\prime} p_{t-1}$ is an vector of error correction terms, $\gamma$ is an $(n-1) \times 1$ matrix of adjustment coefficients, and $\varepsilon_{t}$ is an $n \times 1$ vector of price innovations. The VECM is estimated using log-prices and ten lags.

\begin{tabular}{|c|c|c|c|c|c|c|}
\hline & \multicolumn{3}{|c|}{$\mathrm{AT}$} & \multicolumn{3}{|c|}{ Non-AT } \\
\hline & $\begin{array}{l}\text { Upper } \\
\text { bound }\end{array}$ & $\begin{array}{l}\text { Lower } \\
\text { Bound }\end{array}$ & Midpoint & $\begin{array}{l}\text { Upper } \\
\text { bound }\end{array}$ & $\begin{array}{l}\text { Lower } \\
\text { Bound }\end{array}$ & Midpoint \\
\hline \multicolumn{7}{|c|}{ Panel A. 30 minutes Pre Earnings Announcement } \\
\hline Median & $44.16 \%$ & $40.33 \%$ & $42.25 \%$ & $59.66 \%$ & $55.84 \%$ & $57.75 \%$ \\
\hline Mean & $43.82 \%$ & $40.75 \%$ & $42.29 \%$ & $59.24 \%$ & $56.18 \%$ & $57.71 \%$ \\
\hline St. Error of Mean & $16.96 \%$ & $16.27 \%$ & $16.62 \%$ & $16.27 \%$ & $16.96 \%$ & $16.62 \%$ \\
\hline
\end{tabular}




\begin{tabular}{lllllll} 
Median & $67.58 \%$ & $62.18 \%$ & $64.88 \%$ & $40.00 \%$ & $30.48 \%$ & $35.24 \%$ \\
Mean & $66.52 \%$ & $64.70 \%$ & $65.61 \%$ & $36.78 \%$ & $32.05 \%$ & $34.42 \%$ \\
St. Error of Mean & $18.44 \%$ & $19.65 \%$ & $19.05 \%$ & $18.77 \%$ & $19.22 \%$ & $19.00 \%$ \\
\hline
\end{tabular}




\section{Figure 1: Cumulative average returns and adjusted cumulative average returns}

Figure 1a presents the cumulative average return (CAR) in a five minutes event-window centered at the earnings announcement in 10 second observation intervals. We classify announcements as either good news or bad news, using data obtained from the Institutional Brokers Estimate System (IBES). We collect quarterly median EPS forecast and the standardize surprise is calculated as follows:

$$
\text { Surprise }=\frac{\text { Actual EPS - Median Forecast EPS }}{\text { Standard deviation [Actual EPS - Median Forecast EPS] }}
$$

If the surprise ratio is greater than (less than) than one standard deviation we classify news as good (bad) news. The cumulative average return at time $\tau_{k} \in(-30,30)$ is calculated as follows: $\overline{C A R}_{(-30,30)}=\sum_{j=-30}^{\tau_{k}} \overline{A R}_{j}$ . Firstly we calculate $R_{i, j, k}$ which is the return for $\mathrm{i}$ th firm, $\mathrm{j}$ th time position in the window $(-30,30)$ and $\mathrm{k}$ th announcements. Secondly we calculate $\bar{R}_{i, j}$ which is the average return for ith firm over the number of $\mathrm{Nh}$ announcements where $\mathrm{h}=1$ for the good news and 2 for bad news. $\bar{R}_{i, j}$ is calculated as follow: $\bar{R}_{i, j}=1 / N_{h} \sum_{k=1}^{N_{h}} R_{i, j, k}$ Thirdly we calculate $\overline{A R}_{j}$ that is cross -section aggregation, the average return of $\bar{R}_{i, j}$ for all firms in the sample. $\overline{A R}_{j}$ is calculated as follows: $\overline{A R}_{j}=1 / m_{h} \sum_{i=1}^{m_{h}} \bar{R}_{i, j}$. Figure $1 \mathrm{~b}$ presents the cumulative average abnormal returns (CAARs). The same calculation method is followed, except, abnormal return is to replace $R_{i, j, k}$ by $A R_{i, j, k}=R_{i, j, k}-\overline{\bar{R}}_{j, k}$ where $\overline{\bar{R}}_{j, k}$ is the return of ASX 200 index on $\mathrm{jth}$ time point and $\mathrm{k}$ th announcements. The cumulative average abnormal return is calculated as follows: $\overline{\operatorname{CAAR}}_{(-30,30)}=\sum_{j=-30}^{\tau_{k}} \overline{A A R_{j}}$. where $\overline{A A R}$ is average abnormal returns at the $\mathrm{j}^{\text {th }}$ time point. 
Cumulative Average Returns (CARs)

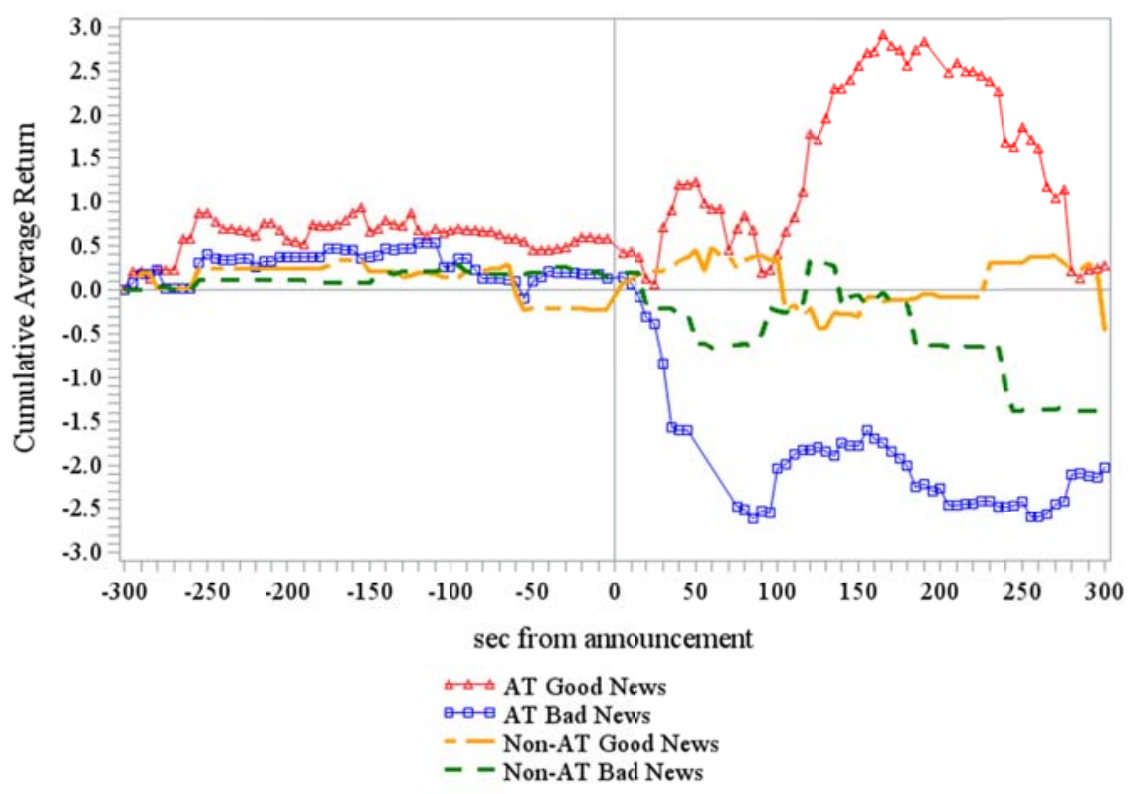

Figure 1b:Cumulative Average Abnormal Returns (CAARs)

Cumulative Average Abnormal Returns (CAARs)

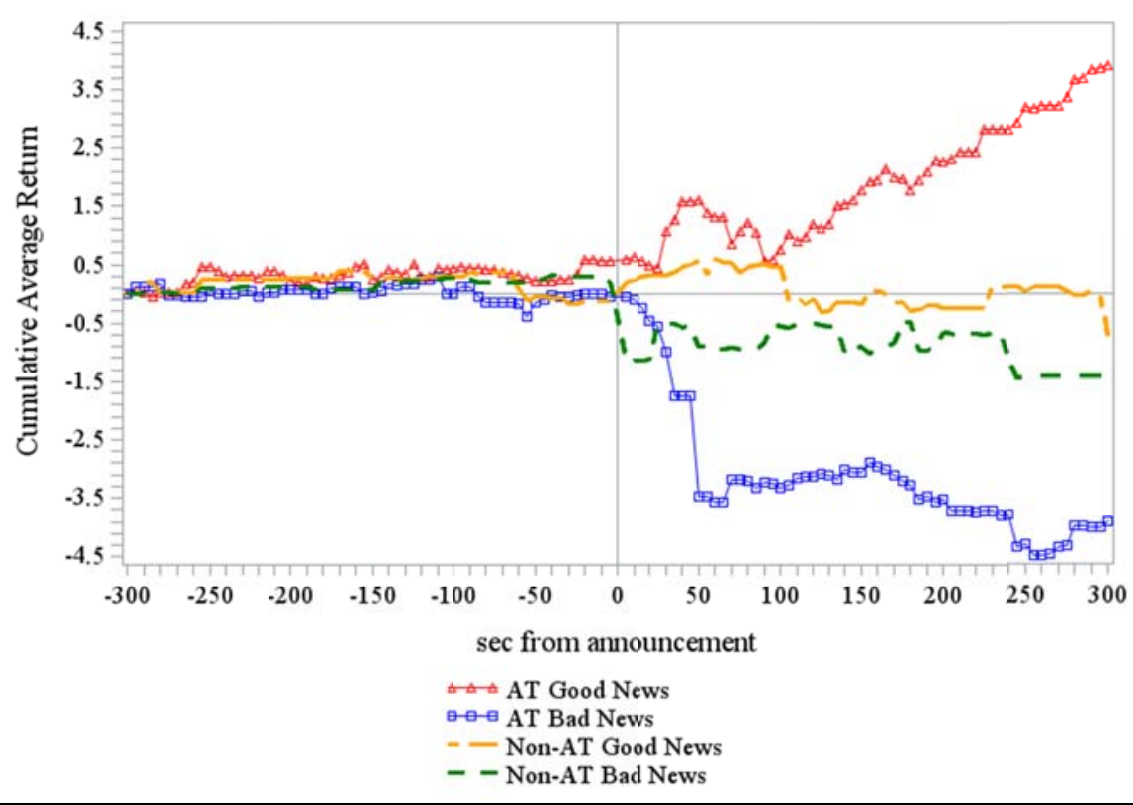




\section{Figure 2: Volume imbalance}

The figure presents the volume imbalance that is calculated as buy volume - sell volume for algorithmic and non-algorithmic trades in a five minutes event-window centered at the earnings announcement in 10 second observation intervals. The event time (earnings announcement time) is defined as time 0 . We classify announcements as either good news or bad news, using data obtained from the Institutional Brokers Estimate System (IBES). We collect quarterly median EPS forecasts and the standardized surprise is calculated as follows:

$$
\text { Surprise }=\frac{\text { Actual EPS }- \text { Median Forecast EPS }}{\text { Standard deviation [Actual EPS - Median Forecast EPS] }}
$$

If the surprise ratio is greater than (less than) than one standard deviation we classify news as good (bad) news. Only announcements classified as either good or bad news are included in our analysis.

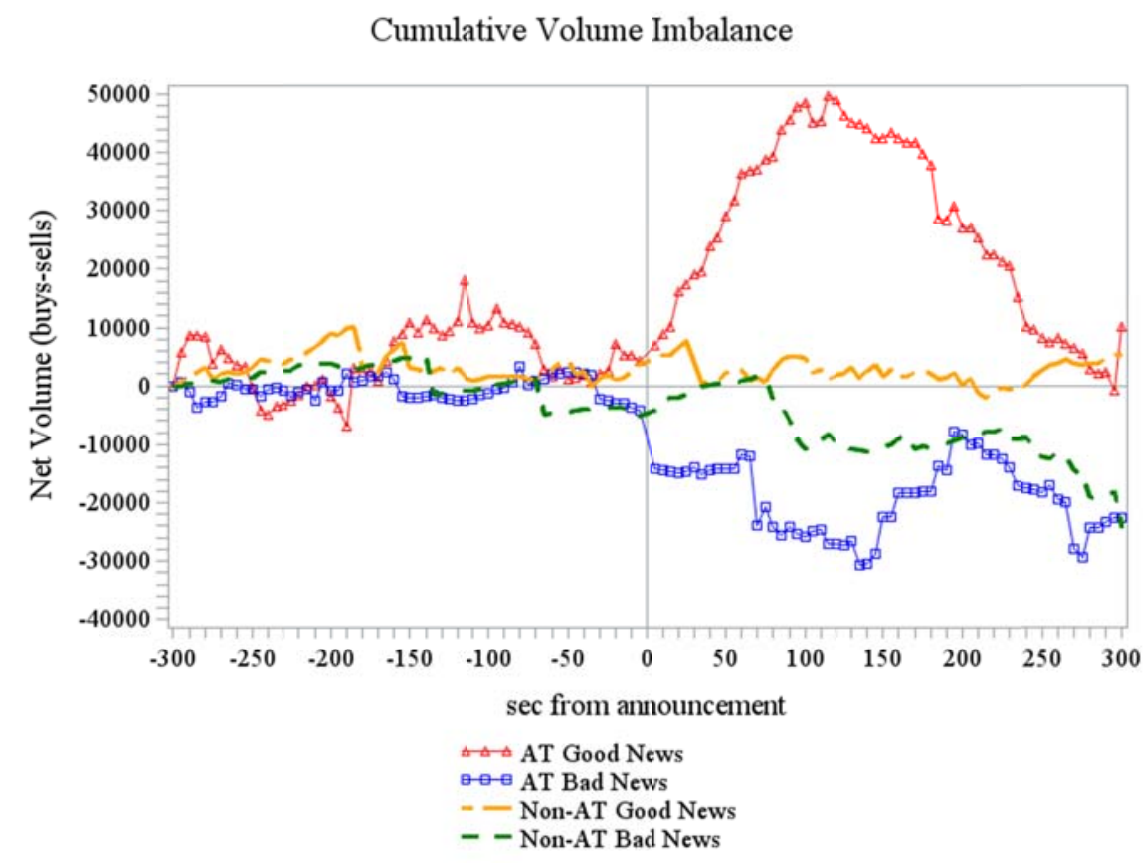

